Universidade de São Paulo

Instituto DE FÍsiCA

Departamento de Física dos Materiais e Mecânica

\title{
Implementação e Aplicações do Método Monte Carlo Reverso para Líquidos Homogêneos
}

\author{
Eudes Eterno Fileti
}

\author{
Orientadora: Prof ${ }^{a} \cdot \mathrm{Dr}^{a}$. Kaline Coutinho
}

\section{Comissão Examinadora:}

Profa. Dra. Kaline Coutinho - (UMC)

Prof. Dr. Mário José de Oliveira - (USP)

Prof. Dr. Luis Carlos Gomide - (UFSCar)
Apresentada junto ao Instituto de Física da Universidade de São Paulo para a obtenção do título de mestre 
Agradeço aos colegas e professores que direta ou indiretamente colaboraram para a produção desta dissertação. Reconheço de forma especial o profissionalismo com 0 qual a professora Kaline Coutinho conduziu este trabalho e a atenção do professor Sylvio Canuto para o meu ingresso e minha permanência no grupo. A eles retrato a ansiedade, nem sempre benéfica, que tive durante o trabalho agradecendo-os pela paciência. Agradeço tambem à Fapesp, ao CNPq e à USP pelas condições de trabalho. 


\section{Conteúdo}

$\begin{array}{lr}\text { Resumo } & 2\end{array}$

$\begin{array}{ll}\text { Abstract } & 3\end{array}$

1 Introdução 4

2 Métodos 8

2.1 Monte Carlo Metropolis . . . . . . . . . . . . . . . . . . . . 8

2.2 Definições e expressões utilizadas . . . . . . . . . . . . . . . . . . . . 12

2.2.1 A Função de Distribuição Radial . . . . . . . . . . . . . . . . . . 12

2.2 .2 O Potencial Intermolecular . . . . . . . . . . . . . . . . . . 14

2.2 .3 Análise angular . . . . . . . . . . . . . . . . . 15

2.2.4 Médias das propriedades termodinâmicas . . . . . . . . . . . . . 17

2.2.5 Correlação estatística . . . . . . . . . . . . . . . 20

2.3 Monte Carlo Reverso . . . . . . . . . . . . . . . . . . . . . . . . . . . . . . 21

2.4 Implementação do método Monte Carlo Reverso . . . . . . . . . . . . . . . 23

2.4.1 Informações sobre o programa para cálculos MCR . . . . . . . . . 23

2.4.2 O gerador de números aleatórios . . . . . . . . . . . . 25

3 Aplicações preliminares $\quad 28$

3.1 Simulação Monte Carlo Metropolis do argônio . . . . . . . . . . . . . . . . . 28

3.2 Simulação Monte Carlo Reverso do argônio . . . . . . . . . . . . . . . . . . 34

4 Resultados 41

4.1 Simulação Monte Carlo Metropolis do oxigênio . . . . . . . . . . . . . . . . 41

4.2 Simulação Monte Carlo Reverso do oxigênio (atômico) . . . . . . . . . . . . . 51

4.3 Simulação Monte Carlo Reverso do oxigênio (molecular) . . . . . . . . . . . 53

5 Conclusões e Perspectivas $\quad 58$

$\begin{array}{ll}\text { Referências } & 60\end{array}$ 


\section{Resumo}

O interesse geral de nosso grupo é estudar sistemas moleculares em fase líquida. Para isto existem várias métodos de simulação. Dentre eles, os mais utilizados são o método Monte Carlo Metropolis e Dinâmica Molecular. Porém ambos necessitam do conhecimento prévio do potencial de interação molecular. Neste trabalho, estudamos um método de simulação recente que embora tenha sido idealizado em 1968 por Kaplow et al só foi formalizado em 1988 por McGreevy et al. Este método é hoje chamado de Monte Carlo Reverso. A vantagem deste método é que ele não necessita do potencial de interação, mas sim do fator de estrutura ou da função de distribuição radial que podem ser obtidos experimentalmente através de espalhamento de raio-X ou de nêutrons. A desvantagem é que ainda existem algumas dúvidas sobre sua confiabilidade e aplicabilidade para sistemas líquidos.

Neste trabalho, realizamos um estudo investigativo procurando adquirir conhecimento a respeito deste método para podermos obter nossas próprias experiências e conclusões. Inicialmente, desenvolvemos um código computacional utilizando o método Monte Carlo Reverso. Depois realizamos simulações de argônio líquido com a finalidade de testar nosso programa e posteriormente aplicamos o método para o oxigênio líquido.

Baseados nos resultados que obtivemos, concluímos que apesar do método Monte Carlo Reverso não ser capaz de descrever a termodinâmica do sistema, ele gera estruturas configuracionais com as mesmas características que as geradas com o Monte Carlo Metropolis. No futuro pretendemos analisar se as configurações geradas com o Monte Carlo Reverso são capazes de reproduzir as propriedades quânticas (dipolo, espectro de absorção, etc) da mesma maneira que o Monte Carlo Metropolis. 


\section{Abstract}

Molecular systems in the liquid phase is part of the general research interest in our group. The computer simulation of liquids may be performed using either Metropolis Monte Carlo or Molecular Dynamics. However, in both cases the simulation requires a previous knowledge of the interatomic potential. An alternative way has been suggested in 1968 by Kaplow et al and formalized by McGreevy et al in 1988. This procedure is called Reverse Monte Carlo. As a distinction, this method does not require any assumption regarding the interatomic potential, but instead tries to reproduce structure factors or radial distribution functions. Though promising there is still a lack of experience on the feasibility of this procedure for liquid systems.

In this work we have performed a detailed investigation of the Reverse Monte Carlo Method for application in liquids. It is of our interest to gain some experience and reach conclusions of the computational and theoretical feasibility for possible large scale applications for the study of spectroscopic and structural properties of molecular liquids. Thus we have developed our own computer code and made applications for the atomic liquid argon and molecular oxygen liquid.

Our studies indicate that Reverse Monte Carlo is not able to describe thermodynamic properties but the configurations generated present the same structural properties of Metropolis Monte Carlo. Hence it is planned for the near future to study the possibility of using these configurations, generated by the Reverse Monte Carlo, to study quantum mechanical properties such as dipole moment and solvatochromic shifts, just as it is usually done using Metropolis Monte Carlo. 


\section{Parte 1}

\section{Introdução}

Hoje em dia estudos sobre a fase líquida da matéria desempenham um papel fundamental na compreensão de fenômenos importantes, tendo em vista que os líquidos estão presentes em várias áreas de pesquisa, principalmente química e biologia, onde são responsáveis por grande parte de processos biológicos e da maioria das reações químicas.

Apesar desta importância, a partir de um ponto de vista histórico, vemos que o estado líquido da matéria tem sido menos estudado do que os estados gasoso e sólido dentro do desenvolvimento geral da física da matéria condensada. Isto se deve à desordem microscópica que os líquidos apresentam pois seus constituintes estão sempre em contínuo movimento. Para as fases gasosa e sólida existem aproximações que simplificam seu estudo, o que não acontece na fase líquida. Assim as propriedades de um líquido são mais difíceis de se calcular do que as propriedades de um sólido ou de um gás. Para um sólido cristalino, considerando a alta simetria e a pequena mobilidade dos átomos as propriedades essenciais podem ser calculadas a partir de uma única configuração atômica que representa uma célula unitária da rede cristalina. Para os gases, considerando a baixa densidade, as propriedades microscópicas são calculadas a partir da configuração de moléculas isoladas.

Como um líquido é composto por um grande número de componentes, um trata- 
mento analítico torna-se inviável. Logo, foi proposto um aparato formal para tratar problemas complexos ou com grande número de componentes, como um líquido por exemplo. Este aparato é a simulação computacional (Allen, 1987; Gould, 1988) que, baseada na Teoria das Probabilidades, além de estudar as propriedades de cada componente individualmente ele também estuda as propriedades de conjuntos de componentes. Esta propriedade de estudar conjuntos de componentes tornam as simulações um meio adequado para a descrição dos sistemas líquidos.

Um dos principais métodos de simulação utilizados atualmente em vários ramos da ciência é o Monte Carlo (Metropolis, 1949) que pode ser descrito como sendo um método que utiliza seqüências de números aleatórios no desenvolvimento de uma simulação. Este método veio a se tornar uma ferramenta de pesquisa somente nas últimas décadas, pois somente com o avanço da tecnologia computacional tal ferramenta tornou-se viável.

Já consolidado e bem aceito há muito tempo pela comunidade científica o Método Monte Carlo hoje em dia é utilizado em diversos ramos da ciência, especialmente em Física. Este método nos fornece informações precisas a respeito de fenômenos complexos, tais como transporte de radiação (Briesmeister, 1993), sistemas caóticos (Sole, 1992), transições de fase (Achahbar, 1995), processos subnucleares em experimentos envolvendo altas energias (Dragovitsch, 1994), entre outros. No campo das ciências moleculares, podemos também utilizar o método Monte Carlo para determinar as propriedades termodinâmicas de sistemas líquidos como capacidade térmica, compressibilidade isotérmica, etc (Allen, 1987). Juntamente com cálculos quânticos podemos utilizá-lo na determinação de propriedades eletrônicas de sistemas moleculares em solução e estudar os efeitos de solventes (Blair, 1989; Coutinho 2000).

Existem hoje muitas técnicas de simulação que são variações do Método Monte Carlo originalmente proposto. Algumas destas variações mais comumente encontradas são: Monte Carlo Metropolis; Monte Carlo Quântico; Monte Carlo Reverso, entre outros. Destas variações a mais apropriada para o estudo de líquidos é o método Monte Carlo Metropolis 
em que procura-se gerar configurações atômicas partindo de um potencial de interação.

Neste trabalho estudaremos uma técnica de simulação relativamente recente, o método Monte Carlo Reverso. Tendo em vista que esse método ainda não está consolidado como o método Monte Carlo Metropolis, este estudo foi realizado de forma investigativa. Procuramos adquirir conhecimento a respeito desta técnica para podermos extrair nossas próprias conclusões quanto a sua confiabilidade e aplicabilidade em sistemas líquidos.

Nosso interesse por este método se manifestou pelo fato dele não requerer um potencial de interação para gerar as configurações atômicas. Na simulação Monte Carlo Reverso, ao invés de ser fornecido o potencial de interação atômico como dado de entrada, são fornecidas informações sobre a estrutura do sistema, como a função de distribuição radial dos átomos ou o seu respectivo fator de estrutura, que podem ser obtidos experimentalmente. Assim sendo, as configurações atômicas são geradas com o objetivo de reproduzir as propriedades estruturais. É interessante observar que com estas configurações podemos estudar os efeitos de solventes nas propriedades eletrônicas de sistemas moleculares.

Neste nosso trabalho desenvolvemos um programa para realizar simulações com o método Monte Carlo Reverso em linguagem FORTRAN. Este programa tem a propriedade de gerar configurações atômicas quaisquer com funções de distribuição radial que mais se assemelhem com a função de referência fornecida. Inicialmente, fizemos estudos preliminares e testamos nosso programa com um sistema amplamente conhecido e estudado através de simulações que é o argônio líquido (Barker, 1976; Frisch, 1968; Howe, 1989a). Posteriormente fizemos estudos inéditos sobre o oxigênio líquido. A escolha desse líquido foi devida a dois motivos básicos: é um sistema simples o suficiente por se tratar de um líquido homogêneo, diatômico e aparentemente sem correlação orientacional (diferentemente do $\mathrm{Cl}_{2}$, $\mathrm{I}_{2}, \mathrm{Br}_{2}$ ) (Andreani,1991), e é complexo o suficiente por não ter um potencial definido na literatura e apresentar caráter magnético.

Neste trabalho utilizamos as simulações Monte Carlo Metropolis como base de comparação para as simulações Monte Carlo Reverso. Desta forma, foi necessária a parametriza- 
ção de um potencial de interação que descrevesse bem o líquido de oxigênio para assim podermos realizar as simulações com o método Monte Carlo Metropolis. Realizamos simulações com os dois métodos para o argônio e para o oxigênio, levando em conta o caráter atômico do primeiro e o caráter molecular do segundo.

No capítulo 2 apresentaremos em maiores detalhes os métodos Monte Carlo Metropolis e Monte Carlo Reverso. Mostraremos as propriedades que calculamos através de nossas simulações, bem como alguns detalhes da implementação do método Monte Carlo Reverso. Em seguida, no capítulo 3, apresentaremos os resultados de nossas simulações preliminares feitas para o argônio líquido, analisando as propriedades e estruturas geradas por ambos os métodos considerados e comparando com os valores já publicados. No capítulo 4 apresentaremos a parametrização do potencial de interação para o oxigênio líquido e os resultados das simulações realizadas para esse sistema. Finalmente, no capítulo 5, a partir da comparação entre os dois métodos, levantaremos nossas conclusões sobre os sistemas estudados e a aplicabilidade do método Monte Carlo Reverso para sistemas moleculares mais complexos. 


\section{Parte 2}

\section{Métodos}

Nas duas seções subseqüentes, descreveremos os dois métodos utilizados neste trabalho, o Monte Carlo Metropolis e o Monte Carlo Reverso, discutindo suas propriedades e observando as diferenças entre as duas técnicas.

\subsection{Monte Carlo Metropolis}

O algoritmo de Metropolis foi inventado por N. Metropolis e colaboradores (Metropolis, 1953) no início da era computacional. O contexto no qual o algoritmo foi criado tornáva-o um método de difícil acesso, já que na época não existiam máquinas capazes de processar o grande volume de operações que ele requer, entretanto esta técnica é hoje poderosa e versátil em simulações em vários ramos da ciência.

O princípio básico do método Monte Carlo Metropolis (MCM) é produzir configurações com a distribuição de probabilidades

$$
P\left(\Gamma_{i}\right)=\frac{\varrho\left(\Gamma_{i}\right)}{Z}
$$

onde $i$ representa um estado do espaço de configurações $\Gamma, Z$ é a função de partição do

sistema e $\varrho\left(\Gamma_{i}\right)$ é a densidade de probabilidade dada por $e^{-\frac{U_{i}}{k T}}$, em que $U_{i}=U\left(\Gamma_{i}\right)$ é a 
energia do estado $i, T$ é a temperatura e $k$ a constante de Boltzmann. O método consiste em fornecer a estimativa para a média de uma propriedade qualquer do sistema, $\langle f\rangle$, de forma simplificada. Utilizando a mecânica estatística tradicional temos que

$$
\langle f\rangle=\frac{1}{Z} \sum_{i}^{M} f\left(\Gamma_{i}\right) \exp \left(-\frac{U\left(\Gamma_{i}\right)}{k T}\right) .
$$

Entretanto utilizando o MCM um certo número M de estados é produzido de acordo com a probabilidade $P\left(\Gamma_{i}\right)$, de forma que a equação anterior, escrita como a média aritmética

$$
\langle f\rangle=\frac{1}{M} \sum_{i}^{M} f\left(\Gamma_{i}\right)
$$

será uma estimativa para a propriedade $f$. O problema, então, se reduz a gerar estados com probabilidade $P\left(\Gamma_{i}\right)$. Isso pode ser resolvido utilizando um procedimento de amostragem ponderada, que gera uma cadeia de Markov. Esta cadeia consiste numa sequência de números gerada por uma matriz de transição $\pi$ que satisfaz condições especiais. Consideremos que um estado $\Gamma_{a}$ exista com uma probabilidade $P_{a}$ e que um estado $\Gamma_{d}$ exista com uma probabilidade $P_{d}$. Para que o estado $\Gamma_{d}$ seja acessível a partir de qualquer estado $\Gamma_{a}$, temos que:

$$
\sum_{a} P_{a} \pi_{a d}=P_{d}
$$

onde $\pi_{a d}$ é a probabilidade de mudar do estado $\Gamma_{a}$ para o estado $\Gamma_{d}$ e possui valor não nulo. A forma de se construir a matriz $\boldsymbol{\pi}$ é utilizar o balanceamento detalhado (Allen, 1987; Oliveira, 1998), isto é, construímos $\pi_{a d}$ tal que:

$$
\pi_{a d} P_{d}=\pi_{d a} P_{a}
$$

Metropolis sugeriu que a matriz $\boldsymbol{\pi}$ fosse a seguinte: 


$$
\pi_{a d}=\left\{\begin{array}{lllll}
1 & \text { se } & P_{a} \leq P_{d} & \text { para } & a \neq d \\
\frac{P_{d}}{P_{a}} & \text { se } & P_{a}>P_{d} & \text { para } & a \neq d \\
1-\sum_{a \neq d} \pi_{a d} & & \text { para } & a=d .
\end{array}\right.
$$

Desta forma a matriz de transição satisfaz todas as propriedades gerais de uma matriz estocástica, característica necessária para que qualquer estado possa ser levado a outro através da aplicação desta matriz.

Uma característica importante deste procedimento é que a função de partição, $Z$, não precisa ser determinada mas somente as probabilidades relativas dos diferentes estados. Isso é muito mais fácil de ser obtido uma vez que é requerida somente a mudança na energia de um estado para outro.

Para um ensemble no qual o número de partículas, $N$, o volume, $V$, e a temperatura, $T$, são mantidos fixos $(N V T)$ podemos obter uma amostragem sobre a qual realizaremos os cálculos dos valores médios das propriedades de interesse. Para isso começamos com uma configuração inicial que é um arranjo de $N$ partículas (no nosso caso moléculas) em uma caixa cúbica. A caixa cúbica é replicada por todo o espaço de forma a termos uma rede infinita, para evitar os efeitos de bordas. Logo, numa simulação, uma molécula que se move na caixa original tem suas réplicas vizinhas se movendo também exatamente no mesmo caminho. Assim se uma molécula deixar a caixa, uma de suas imagens entrará pelo lado oposto gerando a condição de contorno periódica.

Como esse método introduz uma periodicidade no sistema podemos eliminá-la implantando o raio de corte $r_{c}$. Este artifício faz com que a interação entre as moléculas só se dê através de uma distância menor que a metade do lado da caixa impondo que uma molécula não interaja com outra molécula e a respectiva imagem simultaneamente. Outra exigência é de que a caixa tenha a mesma densidade, $N / L^{3}$, que a do sistema real.

O desenvolvimento da simulação se dá a partir de movimentos sucessivos de cada 
átomos dentro da caixa, com uma amplitude máxima determinada. Como muitos destes movimentos podem ser rejeitados por aumentar a energia do sistema (veremos isso adiante), aplicamos um critério de auto-ajuste do deslocamento para que a razão entre o número de movimentos aceitos e movimentos rejeitado fique em torno de 0,5. Esta razão é comumente utilizada (Allen, 1987) e proporciona uma boa razão custo/benefício, onde o custo representa o tempo de processamento e o benefício o número de passos necessários para descorrelacionar as configurações.

A probabilidade de existência de uma configuração qualquer antes de um movimento atômico, na distribuição de Boltzmann é dada por:

$$
P_{a}=\exp \left(-\frac{U_{a}}{k T}\right)
$$

Após um movimento atômico aleatório a probabilidade da nova configuração é:

$$
P_{d}=\exp \left(-\frac{U_{d}}{k T}\right)
$$

Assim, de acordo com as equações 2.7 e 2.8 temos:

$$
\frac{P_{d}}{P_{a}}=\exp \left[-\frac{\left(U_{d}-U_{a}\right)}{k T}\right]=\exp \left(-\frac{\Delta U}{k T}\right) .
$$

Se $\Delta U \leq 0$, ou seja, se o movimento levou o sistema para um estado de energia igual ou mais baixa, permitimos o movimento e colocamos a molécula nesta nova posição, mas se $\Delta U>0$ a configuração será aceita com probabilidade exp $\left(-\frac{\Delta U}{k T}\right)$. Para aceitar a configuração neste caso, geramos um número aleatório $\xi$ uniforme entre 0 e 1, ou seja, $0 \leq \xi<1$. O número é comparado com a probabilidade dada pela expressão 2.9. Se este número for menor ou igual à probabilidade o movimento é aceito, senão ele é rejeitado e a molécula continua na posição anterior ao movimento. A figura 2.1 ilustra as regiões de aceitação e rejeição dos movimentos das moléculas relacionadas aos números aleatórios sorteados. Note que quando $\Delta U \leq 0$, o movimento é sempre aceito visto que qualquer número aleatório sorteado estará abaixo da curva $\exp \left(-\frac{\Delta U}{k T}\right)$, enquanto que quando $\Delta U>$ 0, existe a possibilidade de que os números sorteado estejam acima ou abaixo da curva. 


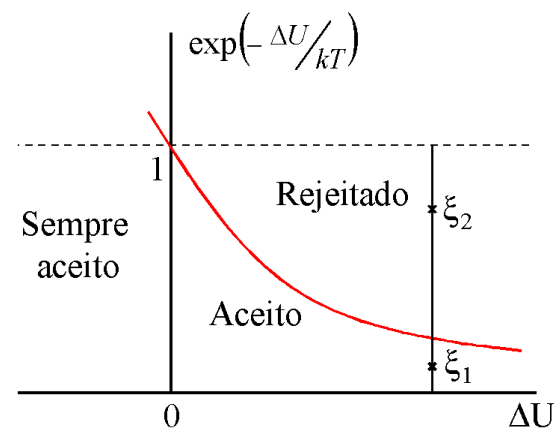

Figura 2.1: Regiões de aceitação e rejeição dos movimentos atômicos. Se $\Delta U \leq 0$ o movimento é sempre aceito. Se $\Delta U>0$, sorteamos um número aléatório entre 0 e 1. Este número pode estar numa região de aceitação no caso de $\xi_{1}$ abaixo da curva, ou numa região de rejeição no caso de $\xi_{2}$, acima da curva.

O procedimento anterior é repetido até que $N$ moléculas sejam visitadas, sendo que cada visita é definida como um passo MCM.

Nos casos das simulações realizadas a partir de uma configuração aleatória a energia inicial é sempre maior que a energia de equilíbrio, assim, como as moléculas são movidas a cada passo, $U$ decrescerá até alcançar o valor de equilíbrio. Para que o sistema alcance o equilíbrio realizamos uma simulação prévia, chamada termalização, que nos fornece uma primeira configuração em equilíbrio para a simulação final. As configurações geradas no equilíbrio são utilizadas no cálculo de várias propriedades estruturais e termodinâmicas. Na subseção 2.2.4 descreveremos o método pelo qual calculamos as propriedades termodinâmicas.

\subsection{Definições e expressões utilizadas}

\subsubsection{A Função de Distribuição Radial}

A descrição de um sistema em fase líquida pode somente ser realizada em termos probabilísticos devido ao fato de um líquido consistir essencialmente de arranjos desordenados de átomos ou moléculas. Estes arranjos são então analisados por meio da Função 
de Distribuição Radial, $g(r)$. Esta função pode ser obtida experimentalmente através de difração de raios-X e nêutrons (Elliott, 1990) e espalhamento de raios-X (Guinier, 1995). Ela dá a probabilidade de encontrar um par de átomos a uma distância $r$, relativa à probabilidade esperada para um sistema de mesma densidade e uma distribuição totalmente aleatória. A distribuição totalmente aleatória é conhecida como distribuição de gás ideal. Na figura 2.2, mostramos uma ilustração esquemática da estrutura de um líquido atômico e a representação dos picos da $g(r)$ correspondente.

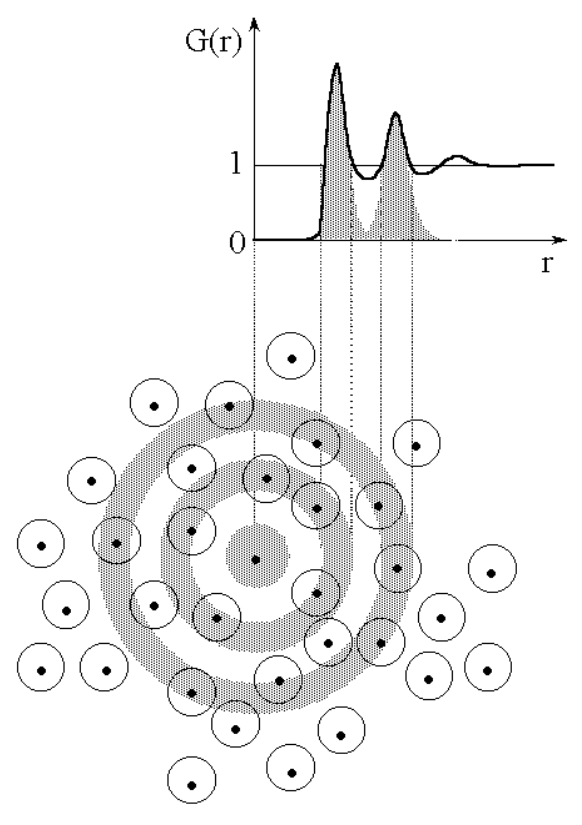

Figura 2.2: Representação esquemática da $\mathrm{g}(\mathrm{r})$.

Teoricamente, a $g(r)$ entre dois átomos pode ser calculada através da integração da função de distribuição de probabilildades do ensemble canônico sobre a posição de todos os átomos do sistema, exceto os dois átomos envolvidos. Evidentemente, num sistema de átomos idênticos a $g(r)$ deve ser calculada como uma média sobre os pares de átomos indistinguíveis. Nas simulações computacionais, a função de distribuição radial entre os átomos do tipo $i$ e átomos do tipo $j, g_{i j}(r)$, é calculada através do histograma de distâncias 
dos pares de átomos $i$ e $j$.

$$
g_{i j}\left(r+\frac{d r}{2}\right)=\frac{n_{i j}(r, r+d r)}{n^{i d}(r, r+d r)} .
$$

onde o numerador, $n_{i j}$, é o número de pares $i j$ que estão separados por uma distância entre $r$ e $r+d r$. Já o denominador, $n^{i d}$, é o número de pares $i j$ equivalentes numa distribuição de gás ideal de mesma densidade, dado por:

$$
n^{i d}(r, r+d r)=\frac{4 \pi}{3} \rho\left[(r+d r)^{3}-r^{3}\right]
$$

É importante salientar que a $g(r)$ é uma função que pode ser calculada diretamente das configurações geradas durante as simulações. Entretanto, experimentalmente esta função não pode ser obtida de forma direta. Primeiramente obtém-se o fator de estrutura que está diretamente associado à intensidade do espalhamento (ou da difração), e em seguida, tomase a tranformada de Fourier do fator de estrutura para obtermos a $g(r)$ do sistema.

O comportamento desta função está fortemente relacionado ao comportamento do potencial intermolecular, que portanto representa outra função importante para a compreensão de uma estrutura líquida. No tópico seguinte descreveremos o potencial que utilizaremos nas simulações com o método MCM.

\subsubsection{O Potencial Intermolecular}

O potencial Lennard-Jones 12-6 (LJ) adicionado ao potencial Coulombiano é um modelo comumente usado para representar as interações atômicas nas simulações e pode ser expresso na seguinte forma:

$$
U\left(r_{i j}\right)=4 \varepsilon_{i j}\left[\left(\frac{\sigma_{i j}}{r_{i j}}\right)^{12}-\left(\frac{\sigma_{i j}}{r_{i j}}\right)^{6}\right]+\frac{q_{i} q_{j}}{r_{i j}} .
$$

onde $\sigma$ e $\varepsilon$ são os parâmetros do potencial LJ, $q_{i}$ é a carga no átomo $i$ e $r_{i j}$ representa a distância entre os átomos das moléculas $i$ e $j$. 
Neste trabalho utilizaremos este potencial porém sem o termo Coulombiano, uma vez que os líquidos em estudos são apolares. Além disso, já é conhecido que para líquidos simples este potencial descreve muito bem suas propriedades termodinâmicas desde que seus parâmetros $\varepsilon$ e $\sigma$ sejam escolhidos apropriadamente (Jorgensen, 1984).

O potencial tem um termo atrativo de longo alcance da forma $-1 / r^{6}$, e uma íngreme parede repulsiva nas distâncias menores que $r \sim \sigma$. Para a descrição de um líquido atômico o potencial dado desta forma fornece geralmente boas informações a respeito das características reais das interações entre os átomos (Jorgensen, 1984).

No caso de um líquido molecular diatômico as interações intermoleculares são intrinsecamente perturbadas pelas interações intramoleculares, ou seja, a interação entre os átomos de uma molécula interfere na ligação entre duas destas moléculas (Tildesley,1987). Neste trabalho não lidaremos com estas interações intramoleculares, portanto, tratamos as moléculas como sendo rígidas, isto é, com ligações fixas.

Podemos, neste caso, escolher sítios nas moléculas e assim utilizar o potencial LJ para determinar a interação total entre as moléculas.

\subsubsection{Análise angular}

Os métodos Monte Carlo Metropolis e Reverso nos fornecem as estruturas do líquido simulado. Através delas podemos realizar uma análise comparativa da distribuição angular e da possível correlação orientacional do líquido em estudo.

O tratamento dado ao líquido atômico é diferente do tratamento dado ao líquido molecular. Para o líquido atômico os vetores que juntam os dois átomos mais próximos que estão na primeira camada de coordenação podem ser chamados de ligações. A função de correlação de três corpos, $g_{3}\left(\mathbf{r}_{1}, \mathbf{r}_{2}, \mathbf{r}_{3}\right)$, pode ser escrita como $g_{3}\left(\left|\mathbf{r}_{1}-\mathbf{r}_{2}\right|,\left|\mathbf{r}_{2}-\mathbf{r}_{3}\right|, \Theta\right)$, onde $\Theta$ é o ângulo entre $\mathbf{r}_{1}-\mathbf{r}_{2}$ e $\mathbf{r}_{2}-\mathbf{r}_{3}$. As informações sobre correlações de três corpos podem então ser obtidas a partir da distribuição angular $B_{123}(\Theta)$. Esta distribuição angular é definida como o número médio de ângulos de ligação entre os átomos 1, 2 e 3, com intervalo 
de ângulo sendo de $\Theta$ a $\Theta+\Delta \Theta$.

Para o caso do líquido poliatômico a análise é mais complicada. Além de calcularmos $B_{123}(\Theta)$ calculamos também a orientação relativa entre as moléculas vizinhas através dos ângulos $\theta_{1}, \theta_{2}$ e $\phi$.

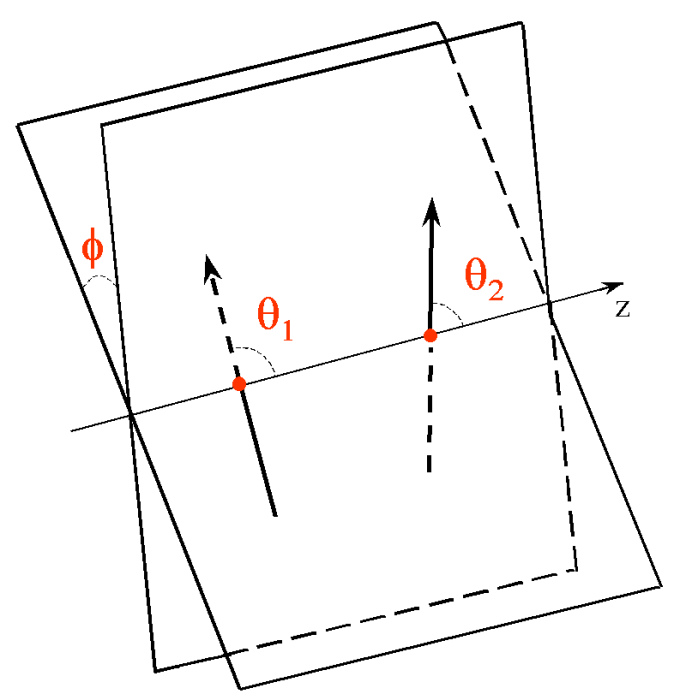

Figura 2.3: Na figura, ilustramos os ângulos $\theta_{1}, \theta_{2}$ e $\phi$ que definem as orientações relativas das moléculas vizinhas.

O eixo $z$ é definido como o eixo que passa no centro de massa de cada molécula. O ângulo $\theta_{i}$ ( $i=1$ ou 2 ) é o ângulo que o vetor que define a direção da molécula $i$ faz com o eixo z. O ângulo $\phi$ por sua vez é o ângulo diedro entre os planos que contêm os vetores que definem as direções das moléculas e o eixo z.

Portanto, para o líquido molecular devemos analisar as distribuições de distâncias e de ângulos para podermos observar uma possível correlação orientacional entre as moléculas. Se as moléculas estiverem orientadas aleatoriamente devemos ter uma distribuição uniforme dos ângulos. Podemos também analisar algumas configurações orientacionais mais comumente consideradas, como as listadas na tabela 2.1. 


\begin{tabular}{ccccc}
\hline \hline Configuração & Símbolo & $\theta_{1}$ & $\theta_{2}$ & $\phi$ \\
\hline Tê & $\perp$ & $0^{\circ}$ a $20^{\circ}$ ou $160^{\circ}$ a $180^{\circ}$ & $0^{\circ}$ a $20^{\circ}$ ou $160^{\circ}$ a $180^{\circ}$ & $0^{\circ}$ a $20^{\circ}$ \\
& & & $70^{\circ}$ a $110^{\circ}$ & \\
Cruz & + & $0^{\circ}$ a $110^{\circ}$ & $70^{\circ}$ a $110^{\circ}$ & $70^{\circ}$ a $110^{\circ}$ \\
& & $160^{\circ}$ a $180^{\circ}$ & $160^{\circ}$ a $180^{\circ}$ ou $0^{\circ}$ a $20^{\circ}$ & \\
Lado a lado & -- & $110^{\circ}$ a $160^{\circ}$ & $0^{\circ}$ a $20^{\circ}$ ou $160^{\circ}$ a $180^{\circ}$ & \\
& & $20^{\circ}$ a $70^{\circ}$ & $20^{\circ}$ a $70^{\circ}$ & $0^{\circ}$ a $20^{\circ}$ \\
Vê & $\vee$ & $110^{\circ}$ a $160^{\circ}$ & $110^{\circ}$ a $160^{\circ}$ & \\
& & $20^{\circ}$ a $70^{\circ}$ & $110^{\circ}$ a $160^{\circ}$ & $0^{\circ}$ a $20^{\circ}$ \\
Paral. desl. & $\backslash \backslash$ & $70^{\circ}$ a $110^{\circ}$ & $20^{\circ}$ a $70^{\circ}$ & $0^{\circ}$ a $20^{\circ}$ \\
\hline Paralela & $\|$ & & $70^{\circ}$ a $110^{\circ}$ &
\end{tabular}

Tabela 2.1: Configurações orientacionais mais comumente consideradas e os respectivos intevalos de ângulos que definem as configurações.

\subsubsection{Médias das propriedades termodinâmicas}

As propriedades termodinâmicas foram determinadas a partir de médias e flutuações da energia geradas durante as simulações e de outras grandezas obtidas das configurações, nos ensembles NVT e NPT. Para o ensemble NVT esses valores médios são: a energia potencial, $\langle U\rangle$, o primeiro virial,

$$
\langle W\rangle=-\left\langle\frac{r}{3} \frac{\partial U}{\partial r}\right\rangle
$$

e o segundo virial,

$$
\langle\Theta\rangle=\left\langle\frac{r}{9} \frac{\partial}{\partial r}\left[\frac{r \partial U}{\partial r}\right]\right\rangle
$$

enquanto que para o ensemble $N P T$ esses valores médios são: a energia potencial, $\langle U\rangle$, o volume, $\langle V\rangle$, e a entalpia configuracional, $\left\langle H_{c}\right\rangle=\langle U+P V\rangle$.

Estas propriedades termodinâmicas são, para o ensemble NVT (Cheung, 1977):

- Energia interna 


$$
\langle E\rangle=\frac{3+v}{2} N k T+\langle U\rangle
$$

onde $v$ são os graus de liberdade, além da translação;

- Calor específico a volume constante molar

$$
\left\langle c_{V}\right\rangle=\frac{3+v}{2} k+\frac{\left\langle\Delta U^{2}\right\rangle}{N k T^{2}}
$$

onde $\left\langle\Delta U^{2}\right\rangle=\left\langle U^{2}\right\rangle-\langle U\rangle^{2}$;

- Pressão

$$
\langle P\rangle=\frac{N k T+\langle W\rangle}{V} ;
$$

- Coeficiente de pressão térmica

$$
\gamma_{V}=\frac{N k}{V}+\frac{\langle\Delta W \Delta U\rangle}{V k T^{2}}
$$

em que $\langle\Delta W \Delta U\rangle=\langle W U\rangle-\langle U\rangle\langle W\rangle$;

- Compressibilidade isotérmica

$$
\kappa_{T}^{-1}=\langle P\rangle-\frac{\left\langle\Delta W^{2}\right\rangle}{V k T}+\frac{\langle\Theta\rangle}{V}
$$

onde $\left\langle\Delta W^{2}\right\rangle=\left\langle W^{2}\right\rangle-\langle W\rangle^{2}$;

- Coeficiente de expansão térmica

$$
\alpha_{P}=\kappa_{T} \gamma_{V}
$$

- Calor específico à pressão constante molar

$$
\left\langle c_{P}\right\rangle=\left\langle c_{V}\right\rangle+\frac{V T \kappa_{T} \gamma_{V}^{2}}{N} .
$$

Para o ensemble NPT temos: 
- Entalpia

$$
\langle H\rangle=\frac{3+v}{2} N k T+\left\langle H_{c}\right\rangle
$$

onde $v$ são os graus de liberdade das partículas, além da translação;

- Calor específico à pressão constante

$$
c_{P}=\frac{3+v}{2} k+\frac{\left\langle\Delta H_{c}^{2}\right\rangle}{N k T^{2}}
$$

onde $\left\langle\Delta H_{c}^{2}\right\rangle=\left\langle H_{c}^{2}\right\rangle-\left\langle H_{c}\right\rangle^{2}$;

- Compressibilidade isotérmica

$$
\kappa_{T}=\frac{\left\langle\Delta V^{2}\right\rangle}{\langle V\rangle k T}
$$

onde $\left\langle\Delta V^{2}\right\rangle=\left\langle V^{2}\right\rangle-\langle V\rangle^{2}$;

- Coeficiente de expansão térmica

$$
\alpha_{P}=\frac{1}{T}+\frac{\left\langle\Delta V \Delta H_{c}\right\rangle}{\langle V\rangle k T^{2}}
$$

onde $\left\langle\Delta V \Delta H_{c}\right\rangle=\left\langle V H_{c}\right\rangle-\left\langle H_{c}\right\rangle\langle V\rangle$

- Coeficiente de pressão térmica

$$
\gamma_{V}=\frac{\alpha_{P}}{\kappa_{T}}
$$

- Calor específico a volume constante molar

$$
c_{V}=c_{P}+\langle V\rangle T \frac{\alpha_{P}^{2}}{N \kappa_{T}} .
$$

A demonstração destas expressões pode ser feita partindo das definições de cada propriedade (Reif, 1965) e da função de partição de cada ensemble.

Os dois ensembles que mencionamos foram escolhidos para a realização das simulações por se adequarem aos cálculos das propriedades dos líquidos. A diferença básica entre os dois é que no ensemble NPT o volume flutua, assim durante a simulação além dos movimentos das moléculas existe também uma mudança aleatória no volume. Um novo valor do 
volume é aceito de acordo com a probabilidade exp $\left(-\frac{\Delta H_{c}}{k T}+N \ln \frac{V_{d}}{V_{a}}\right)$ onde o último termo está relacionado ao escalonamento das posições das moléculas na caixa, de modo que não fique espaços vazios na caixa quando o volume aumente ou que não fiquem moléculas fora da caixa quando o volume diminui. A aceitação ou rejeição desse novo volume é feita de modo análogo ao discutido na seção 2.1 para a descrição no ensemble $N V T$.

\subsubsection{Correlação estatística}

Analisando a correlação estatística vamos calcular o intervalo de configurações para que o sistema evolua de uma configuração para outra de forma que esta última não tenha correlação estatística com a primeira. Para podermos calcular médias ou comparar as estruturas de forma eficiente devemos nos certificar que estas estruturas estejam com menos de $10 \%$ de correlação estatística, ou seja, separadas por um intervalo de correlação $\sim 2 \tau$.

O intervalo de correlação estatística é definido como:

$$
\tau=\int_{0}^{\infty} C(i) d i
$$

onde

$$
C(i)=\frac{\left\langle\Delta U_{j} \Delta U_{i+j}\right\rangle}{\left\langle\Delta U^{2}\right\rangle}
$$

é função de auto-correlação da energia configuracional e $i$ representa o número de passos MC. Como as simulações são finitas não podemos calcular $C(i)$ para valores de $i$ muito grande, o que torna a integração da equação 2.28 inviável. Para resolver este problema é necessário fazer um ajuste dos valores de $C(i)$ por uma função integrável neste intervalo. Um ajuste sugerido para processos Markovianos (Krätschmer, 1976; Tang, 1987) é dado por

$$
C(i)=c_{1} e^{-\frac{i}{\tau_{1}}}+c_{2} e^{-\frac{i}{\tau_{2}}}
$$

de forma que:

$$
\tau=c_{1} \tau_{1}+c_{2} \tau_{2}
$$


onde $c_{1}, \tau_{1}, c_{2}$ e $\tau_{2}$ são obtidos do ajuste. Assim, como desejamos realizar cálculos com configurações estatisticamente independentes, devemos através de cálculos preliminares determinar o intervalo de correlação.

\subsection{Monte Carlo Reverso}

A estrutura de sistemas em fase líquida por muito tempo tem sido estudada através de difração de raios-X. Contudo, a interpretação desses resultados é difícil quando comparada com a interpretação para um sistema cristalino. Para contornar esta dificuldade um método de simulação, baseado no método Monte Carlo Metropolis, vem sendo estudado e testado durante esta última década, o método Monte Carlo Reverso. De acordo com alguns estudos (McGreevy, 1988; Howe, 1989b) este método possibilita a interpretação dos resultados destes experimentos de difração partindo do fator de estrutura do sistema desordenado, ou equivalentemente de sua função de distribuição radial de pares, como descrita na seção 2.2.1.

Em 1968, Kaplow et al. realizaram uma simulação pioneira utilizando este método. Eles determinaram a simetria de um sistema partindo das funções de distribuição radial do selênio vítreo. Trabalhos como este, que utilizavam o Método Monte Carlo Inverso (ou Reverso) já haviam sido publicados mesmo antes do trabalho de McGreevy em 1988, que propõe um algoritmo formal e abrangente para realizar simulações via Monte Carlo Reverso (MCR).

Este método também é markoviano e usa como dados de entrada para a simulação uma $g(r)$ de referência que pode ser experimental, obtida a partir de difração de nêutrons ou de raios-X para o líquido, ou retirada de uma simulação prévia. Portanto, no MCR desejamos gerar configurações de $N$ moléculas em um volume, $V$, que correspondam a uma função de distribuição radial de referência, $g_{r e f}(r)$.

Para isso começamos com uma configuração inicial qualquer levando em conta o 
método das imagens e as condições periódicas de contorno. Aqui impomos também uma distância de superposição, que impede que os átomos aproximem-se a distâncias não físicas. Assim sempre que a molécula se aproximar de outra por uma distância menor que a distância de superposição seu movimento é automaticamente rejeitado. É interessante observar que a configuração inicial é gerada satisfazendo o critério de não existir nenhuma molécula com distância interatômica menor que a distância de superposição.

No início da simulação determinamos a primeira função de distribuição radial, $g_{a}(r)$, e em seguida calculamos o quadrado da diferença entre as funções $g_{r e f}$ e $g_{a}$

$$
\chi_{a}^{2}=\sum_{i=1}^{m}\left[g_{r e f}\left(r_{i}\right)-g_{a}\left(r_{i}\right)\right]^{2}
$$

em que a soma é tomada sobre todos os pontos da função. O índice $a$ indica a $g(r) a$ ntes do movimento.

Em seguida, movemos as moléculas aleatoriamente e calculamos a nova função de distribuição radial $g_{d}(r)$ e

$$
\chi_{d}^{2}=\sum_{i=1}^{m}\left[g_{r e f}\left(r_{i}\right)-g_{d}\left(r_{i}\right)\right]^{2} .
$$

Aqui o índice $d$ indica a $g(r)$ depois do movimento.

Se a nova configuração produzir uma $g(r)$ que se assemelhe mais com a $g_{r e f}(r)$, ou seja, $\chi_{d}^{2} \leq \chi_{a}^{2}$, o movimento atômico é permitido e esta nova configuração é aceita. Por outro lado, se a nova configuração fizer com que a $g(r)$ se diferencie mais da $g^{\text {ref }}$, ou seja, se $\chi_{d}^{2}>\chi_{a}^{2}$ ela ainda pode ser aceita, porém com probabilidade $\exp \left(-\frac{\Delta \chi^{2}}{2 \delta^{2}}\right)$, onde $\Delta \chi^{2}=\chi_{d}^{2}-\chi_{a}^{2}$ e $\delta$ representa a incerteza experimental ${ }^{1}$ ou uma tolerância entre as funções $g(r)$ calculadas e de referência.

Este procedimento é iterativo, partindo do movimento das moléculas da configuração inicial, portanto $\chi^{2}$ descrescerá (caso comece de uma configuração aleatória) até atingir um valor de equilíbrio em torno do qual ficará flutuando. Neste estágio são geradas configurações de onde extraímos as propriedades estruturais.

\footnotetext{
${ }^{1}$ Veremos na seção 3.2 que o $\delta$ é um parâmetro importante nas simulações MCR.
} 
Este método é muito parecido com o MCM já que a principal diferença entre os dois tipos de simulação é que no MCR utilizamos como critério de aceitação ou rejeição de configurações a comparação de $\chi^{2}$ antes e depois do movimento de uma molécula, enquanto que no MCM utilizamos a comparação das energias potenciais, $U$.

\subsection{Implementação do método Monte Carlo Reverso}

Os cálculos MCM realizados neste trabalho foram executados pelo programa DICE (Coutinho, 1997). Para os cálculos com o método MCR desenvolvemos um novo código. Nas seções abaixo damos alguns detalhes de sua implementação.

\subsubsection{Informações sobre o programa para cálculos MCR}

Este código baseou-se no caráter fundamentalmente iterativo do método MCR, pelo qual devemos encontrar uma função que reproduza uma função de distribuição radial de referência dentro de um erro estimado.

Durante seu desenvolvimento nos preocupamos com a versatilidade do programa. Assim sendo, criamos 16 subrotinas cujas funcionalidades descreveremos a seguir.

Três subrotinas, read_num, read_word e read_exp, foram desenvolvidas para lerem as variáveis iniciais da simulação. A primeira lê as variáveis numéricas, a segunda lê as variáveis caracteres e a última lê a função de distribuição radial de entrada que são passadas para o programa. Para cada simulação são criados arquivos em separado que contém todas as informações iniciais necessárias, tais como: número de passos de esfriamento $^{2}$, número de passos de termalização, número de passos da simulação, etc.

As estruturas MCR são obtidas iterativamente a partir de duas configurações iniciais que o programa pode gerar ou de uma configuração pré-existente que é lida pela

\footnotetext{
${ }^{2}$ É um procedimento que precede a termalização e que tem por objetivo baixar o valor de $\Delta \chi^{2}$ do sistema até valores razoáveis antes de iniciar o ciclo de comparações.
} 
subrotina read_dt. Através das subrotinas conf_ord e conf_rand o programa gera uma configuração ordenada e uma configuração aleatória, respectivamente. Este procedimento nos permitiu verificar a importância da configuração inicial para a eficiência da simulação. Na figura 2.4 vemos estas estruturas e suas respectivas $g(r)^{s}$. Nesse ponto impomos a distância mínima em que os átomos ou as moléculas podem aproximar entre si, este teste é feito pela subrotina overlap.
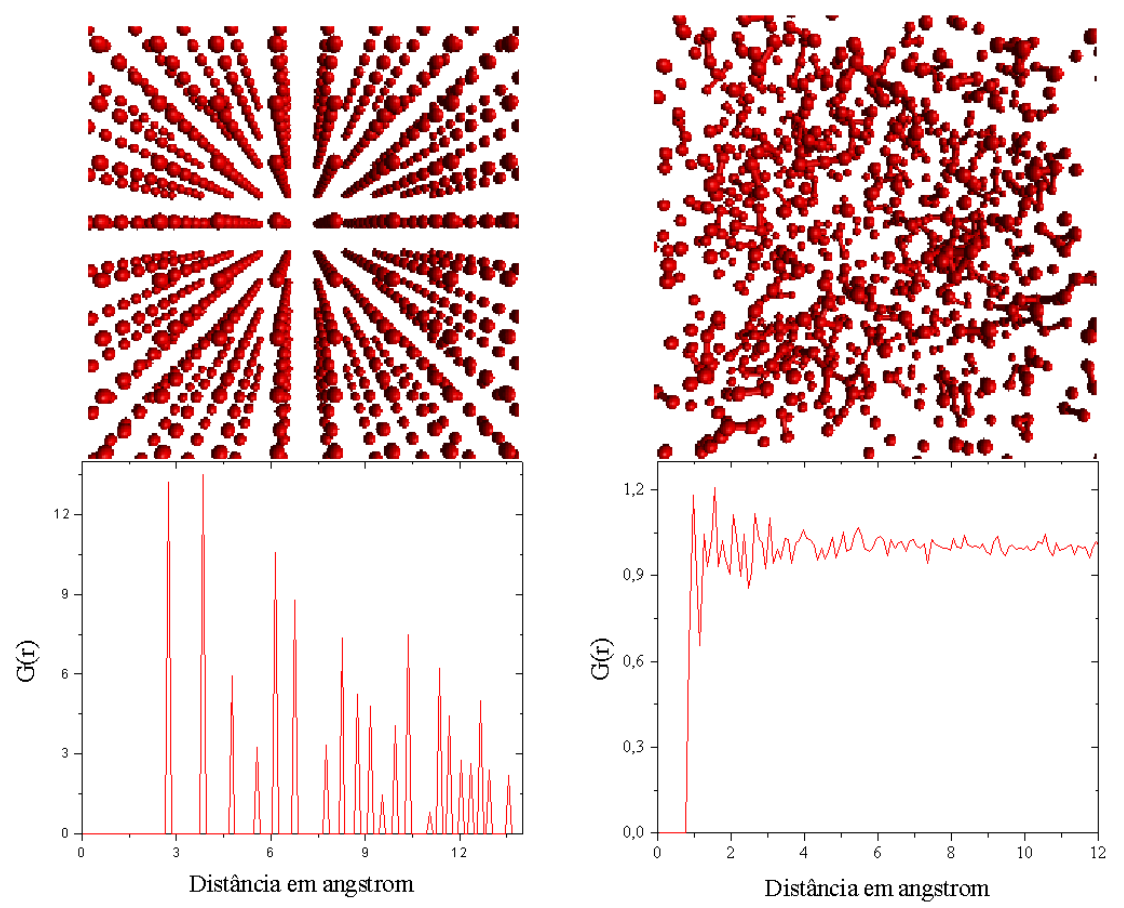

Figura 2.4: As configurações iniciais e as respectivas $g(r)^{s}$ para um sistema contendo 1000 átomos. A direita temos uma configuração aleatória e a esquerda uma configuração ordenada.

A partir de uma destas configurações calculamos com a subrotina hist_initial o primeiro histograma de distâncias dos pares de átomos $i$ e $j$ usando a definição 2.10 normalizado pela subrotina normaliza para o cálculo da $g(r)$.

Para o cálculo da primeira função de distribuição radial, $g_{a}(r)$, movemos um átomo da configuração inicial utilizando a subrotina move_i. De posse da $g_{a}(r)$ calculada e da $g_{r e f}(r)$, o programa pode fornercer o primeiro $\chi_{a}^{2}$, de forma a começar o ciclo de compara- 
ções, já que a cada passo MCR obtemos o novo $\chi^{2}$. Para realizar esse ciclo o programa dispõe das subrotinas calc_chi que calcula o valor de $\chi^{2}$, calc_hist que atualiza o histograma de distâncias e gr_new e gr_norm que calculam, atualizam e normalizam a $g(r)$ a cada passo. O teste de aceitação ou rejeição de um movimento é realizado no final de cada ciclo.

Finalmente, os arquivos de saída são salvos em formatos convenientes pelas subrotinas: write_dt, que salva todas as informações suficientes para reinicializar uma simulação, write_cf que salva as configurações em formato xyz e gr_norm que salva as $g(r)^{s}$.

Desses arquivos de saída extraímos as informações estruturais, tais como distâncias interatômicas e ângulos como definidos anteriormente $\left(\theta_{1}, \theta_{2}\right.$ e $\left.\phi\right)$ de maneira que possamos realizar a estatística sobre as configurações geradas.

Uma representação esquemática do funcionamento do programa é dada na figura 2.5 .

\subsubsection{O gerador de números aleatórios}

Numa simulação usual, milhões de números aleatórios são necessários durante o processo. Logo, a escolha de um bom gerador de números aleatórios é de fundamental importância para eficiência de uma simulação. Atualmente os métodos de gerar e lidar com números aleatórios estão razoavelmente bem estabelecidos. Assim temos diversos geradores de números aleatórios dos quais podemos fazer uso de acordo com nossas conveniências.

Utilizamos para nossos cálculos um algoritmo conhecido como ran2 (Press, 1992a) cuja subrotina foi retirada do Numerical Recipes (Press, 1992b), tem periodicidade superior

a $2 \times 10^{18}$ iterações. Esse gerador, considerando as limitações de um computador atual é perfeito. Seu algoritmo tal qual implementado no nosso programa está mostrado à frente: 


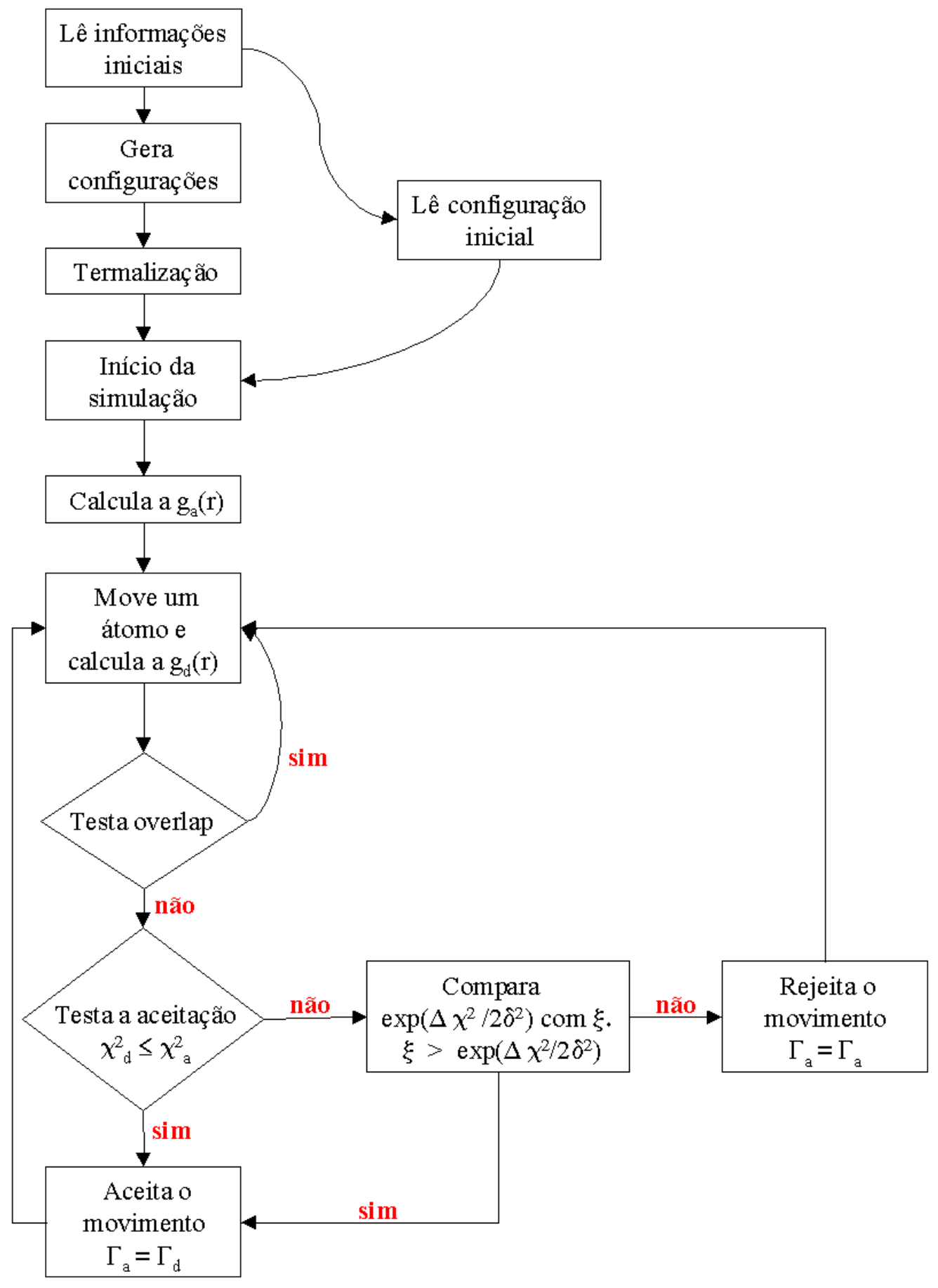

Figura 2.5: Representação esquemática do funcionamento do programa para os cálculos MCR. 


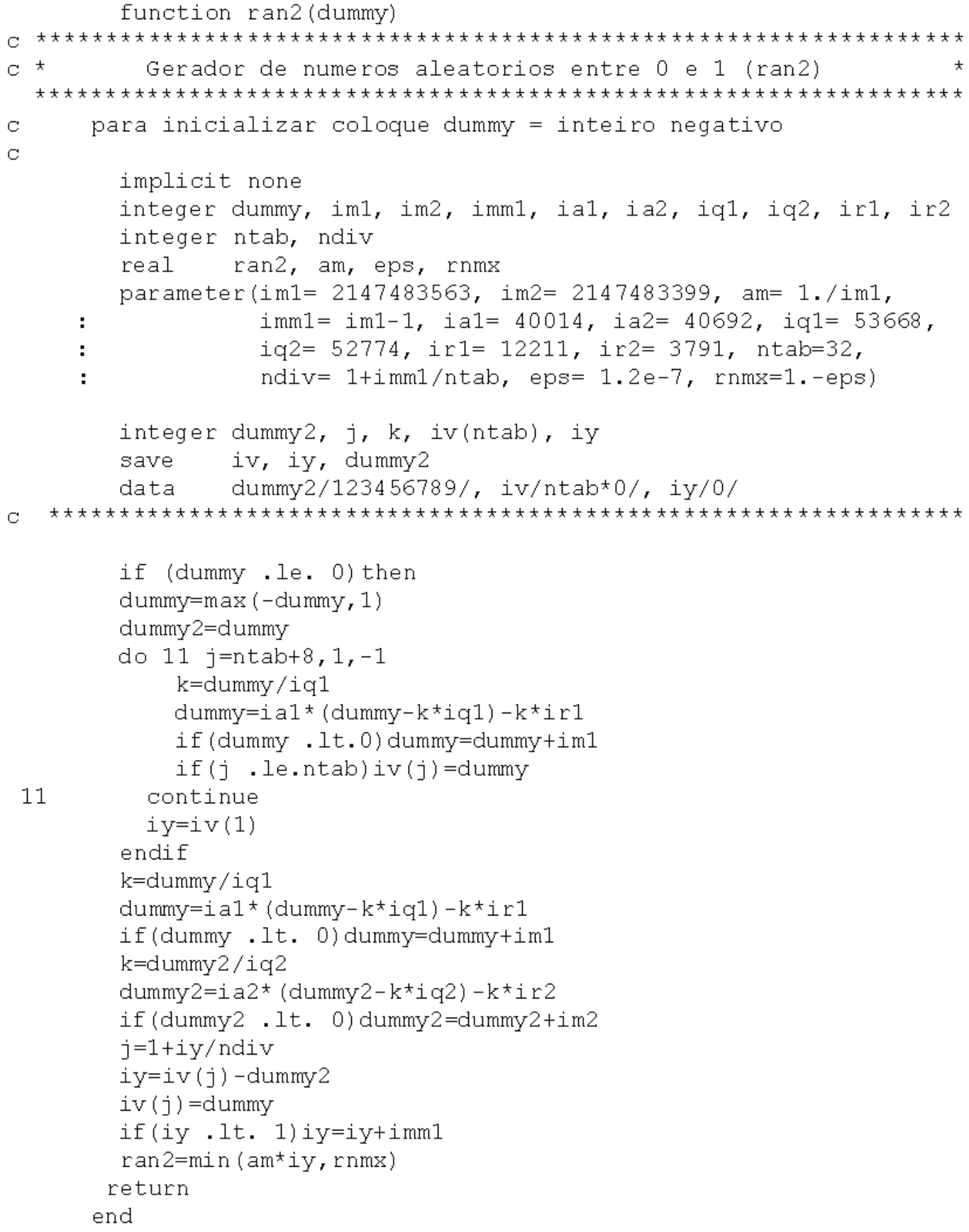




\section{Parte 3}

\section{Aplicações preliminares}

Neste capítulo apresentaremos nossos primeiros resultados de simulações com o método Monte Carlo Reverso (MCR) obtidos com o programa que desenvolvemos e discutimos no capítulo anterior.

Com o objetivo de testar o programa, escolhemos um sistema simples e que apresenta muitos resultados experimentais disponíveis. Este sistema é o argônio.

Adicionalmente, para entendermos melhor as vantagens e deficiências do MCR, realizamos simulações com o método convencional (MCM) e fizemos comparações diretas das propriedades estruturais e termodinâmicas calculadas com as configurações geradas pelos dois métodos de simulação.

Portanto, neste capítulo, além de testarmos nosso programa, iniciamos uma análise detalhada do método MCR.

\subsection{Simulação Monte Carlo Metropolis do argônio}

Nossas simulações MCM para o argônio líquido foram realizadas com 1000 átomos sob uma temperatura $T=130 K$ no ensemble NVT. A densidade do líquido a esta tempe- 
ratura é $\rho=1,066 \mathrm{~g} / \mathrm{cm}^{3}$ (Frisch, 1968). Os detalhes sobre a simulação estão mostrados na tabela 3.1.

\begin{tabular}{cc}
\hline \hline $\mathrm{N}^{o}$ de átomos $(N)$ & 1000 \\
Temperatura $(T)$ & $130 K$ \\
Densidade $(\rho)$ & $1,066 \mathrm{~g} / \mathrm{cm}^{3}$ \\
Tamanho da caixa $(L)$ & $39,625 \AA$ \\
Raio de $\operatorname{corte}\left(r_{c}\right)$ & $19,813 \AA$ \\
$\mathrm{N}^{o}$ de passos $\mathrm{MCM}$ & 75.000 .000 \\
Tempo de CPU & $\approx 30 h$ \\
Razão aceitação/rejeição & $50 \%$ \\
\hline \hline
\end{tabular}

Tabela 3.1: Detalhes da simulação MCM do argônio líquido realizada no ensemble NVT. O tempo de CPU é de uma Alpha Digital $(4100 / 500 \mathrm{MHz})$

Para descrever a interação atômica utilizamos o potencial Lennard-Jones (LJ) com os parâmetros determinados por Michels e Wijker $(\sigma=3,405 \AA$ e $\varepsilon=0,2378 \mathrm{kcal} / \mathrm{mol})($ Michels, 1949). O sistema alcançou o equilíbrio por volta de 500.000 passos simulados na termalização, como mostra a figura 3.1. Após a termalização realizamos uma simulação de 75.000.000 de passos MCM, através da qual calculamos as propriedades termodinâmicas para o líquido.

Podemos observar a partir da figura 3.2 a convergência de duas propriedades calculadas. Do lado direito temos o valor médio da energia por átomo, $\langle U / N\rangle$, e do lado esquerdo o valor médio do calor específico, $\left\langle c_{V}\right\rangle$. Vemos que à medida que o processo se desenvolve as propriedades vão convergindo para seu valor médio. Tanto para energia quanto para capacidade térmica foram necessários $~ 1,5$ milhões de passos MCM para que seus valores médios fossem atingidos. As demais propriedades também apresentam boa convergência, exceto a pressão, que possui difícil convergência por apresentar grandes flutuações. Estudos anteriores mostram que esta propriedade é muito sensível a pequenas variações da densidade (Coutinho, 1997). Neste trabalho, verificamos que o aumento em $3 \%$ na densidade utilizada na simulação aumenta em mais de $400 \%$ o valor da pressão, elevando este de -6 atm para $19 \mathrm{~atm}$, que é o patamar experimental enquanto as outras propriedades variam pouco, não mais que $3 \%$. 


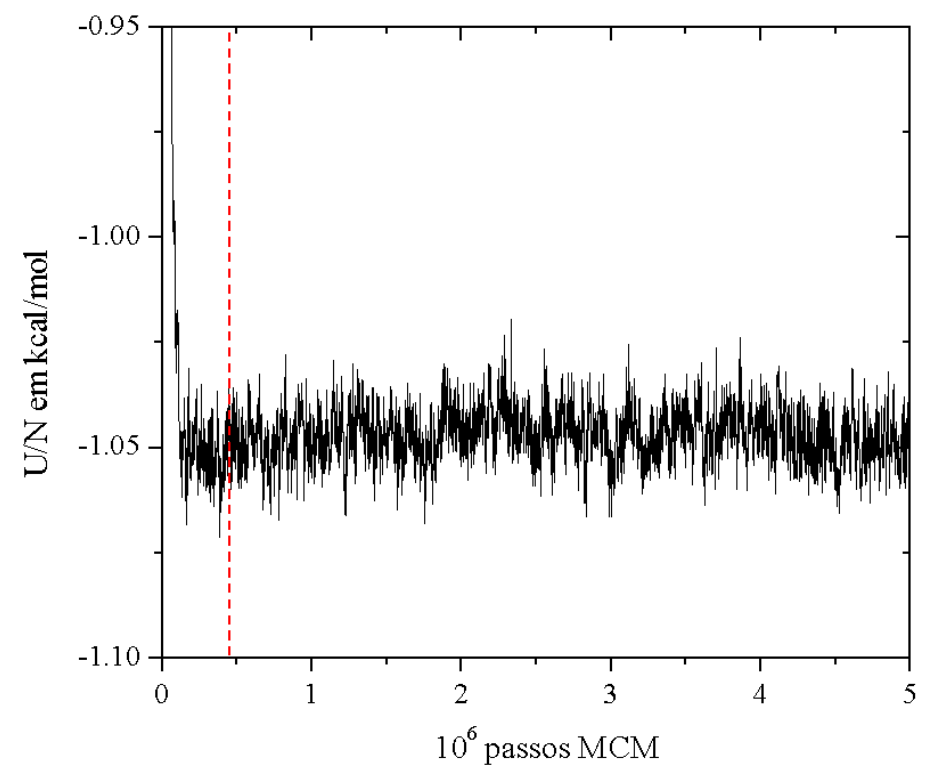

Figura 3.1: Processo de simulação do líquido de Argônio.
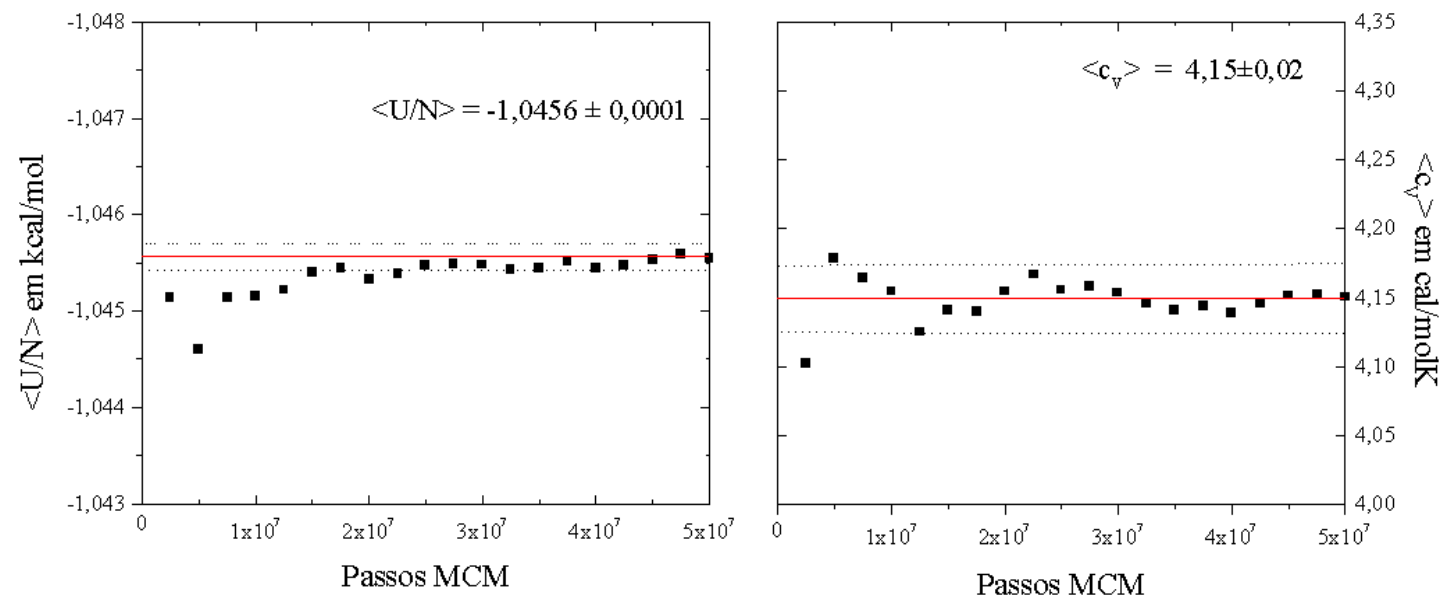

Figura 3.2: Energia por átomo $\langle U / N\rangle$ e da capacidade térmica $\left\langle c_{V}\right\rangle$ em função do número de passos MCM. 


\begin{tabular}{ccc}
\hline \hline Propriedade & Experimental & MCM \\
$\langle U / N\rangle \mathrm{em} \mathrm{kcal} / \mathrm{mol}$ & $-1,015$ & $-1,0456 \pm 0,0001$ \\
$c_{V} \mathrm{cal} / \mathrm{molK}$ & 4,061 & $4,15 \pm 0,02$ \\
$\gamma_{V} \mathrm{em} \mathrm{atm} / \mathrm{K}$ & 8,00 & $8,5 \pm 0,6$ \\
$10^{4} \kappa_{T} \mathrm{em} \mathrm{atm}^{-1}$ & 14,00 & $13 \pm 2$ \\
$p$ em atm & 20,01 & $-6 \pm 2$ \\
\hline \hline
\end{tabular}

Tabela 3.2: Valores calculados e experimentais (Frisch, 1968) das propriedades termodinâmicas do argônio à temperatura de $130 \mathrm{~K}$ com $\rho=1,066 \mathrm{~g} / \mathrm{cm}^{3}$.

Na tabela 3.2 podemos observar também, que os valores simulados para as propriedades estão em bom acordo com os valores experimentais. A diferença entre os valores calculados e os valores experimentais está num intervalo de 1,9\% para a compressibilidade isotérmica, $\kappa_{T}$, a $5,5 \%$ para o calor específico, $c_{V}$. Embora as incertezas experimentais não estejam mostradas elas variam de 10 a $20 \%$.

A função de distribuição radial calculada é mostrada na figura 3.3 onde podemos observar seu comportamento em relação à função de distribuição radial experimental. A função experimental foi obtida por Mikolaj e Pings em 1967 através de espalhamento de raios-X de baixo ângulo ${ }^{1}$. Podemos observar a boa concordância entre a posição do primeiro pico assim como a posição onde começa a $g(r)$, através da figura 3.3 e da tabela 3.3 . Vemos também que o segundo pico está em bom acordo com o experimento.

\begin{tabular}{|c|c|c|c|c|c|c|}
\cline { 2 - 5 } \multicolumn{1}{c|}{} & \multicolumn{2}{c|}{$1^{\circ}$ pico } & \multicolumn{2}{c|}{$2^{o}$ pico } & \multicolumn{1}{c|}{} \\
\cline { 2 - 5 } \multicolumn{1}{c|}{} & máx. & mín. & $\mathrm{N}_{c}$ & máx. & mín. & $\mathrm{N}_{c}$ \\
\hline MCM & $3,75 \AA$ & $5,45 \AA$ & 11 átomos & $6,65 \AA$ & $8,65 \AA$ & 44 átomos \\
\hline Exp & $3,62 \AA$ & $5,37 \AA$ & 11 átomos & $7,00 \AA$ & $>8,00 \AA$ & $>23$ átomos \\
\hline
\end{tabular}

Tabela 3.3: Comparação da posição e dos respectivos números de coordenaçãodos dos picos calculado e experimental (Mikolaj, 1967). Para o segundo pico, como vemos na figura 3.3 a extensão é maior que 8,0Å, portanto seu número de coordenação mostrado é inferior ao real.

Para a análise estrutural, foi necessário um número razoável de configurações descorrelacionadas de forma a proporcionar boas médias. A análise de quão descorrela-

\footnotetext{
${ }^{1}$ Esta técnica de espalhamento produz $g(r)^{s}$ com grande precisão para grandes valores de $r$ e pequena precisão para pequenos valores de $r$.
} 


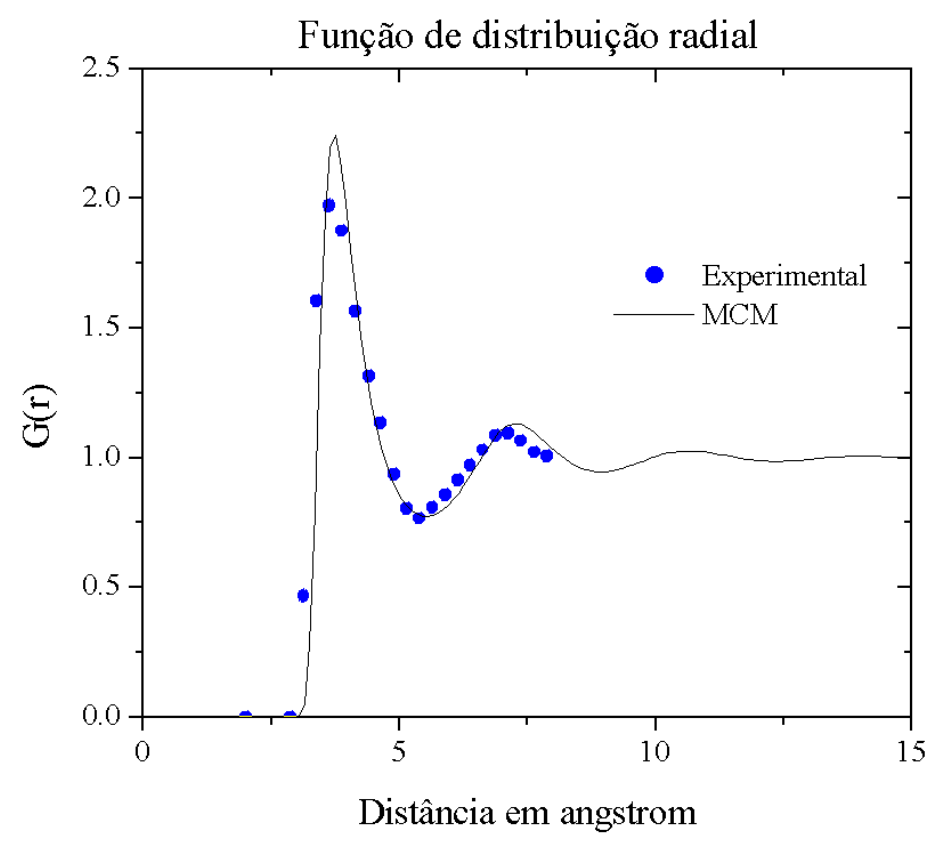

Figura 3.3: Funções de distribuição radial calculada e experimental (Mikolaj, 1967) para o líquido de argônio a $130 \mathrm{~K}$.

cionadas são as configurações usadas foi feita através do intervalo de correlação, $\tau$. A figura 3.4 mostra a função de autocorrelação da energia, o ajuste para esta função assim como os valores para as constantes da curva de ajuste. Se considerarmos que uma correlação de apenas $6 \%$ é suficiente para obtermos estruturas descorrelacionadas, através da figura concluímos que as configurações estarão descorrelacionadas se forem separadas por 250.000 passos MCM. Assim, de uma simulação de 75.000 .000 de passos, foi produzido um conjunto de 300 configurações descorrelacionadas para o cálculo das médias das conformações estruturais.

A análise da distribuição angular pode ser feita através de $B_{123}(\theta)$ definido na seção 2.2.3 e mostrado na figura 3.5. Nesta figura podemos observar que a maior quantidade de átomos vizinhos formam um ângulo de $\sim 65^{\circ}$ e que não existem ângulos inferiores a $\sim 45^{\circ}$. Esta distribuição angular pode ser interpretada utilizando as informações da $g(r)$, pois nela temos que a maior quantidade de átomos vizinhos está separado por uma distância 


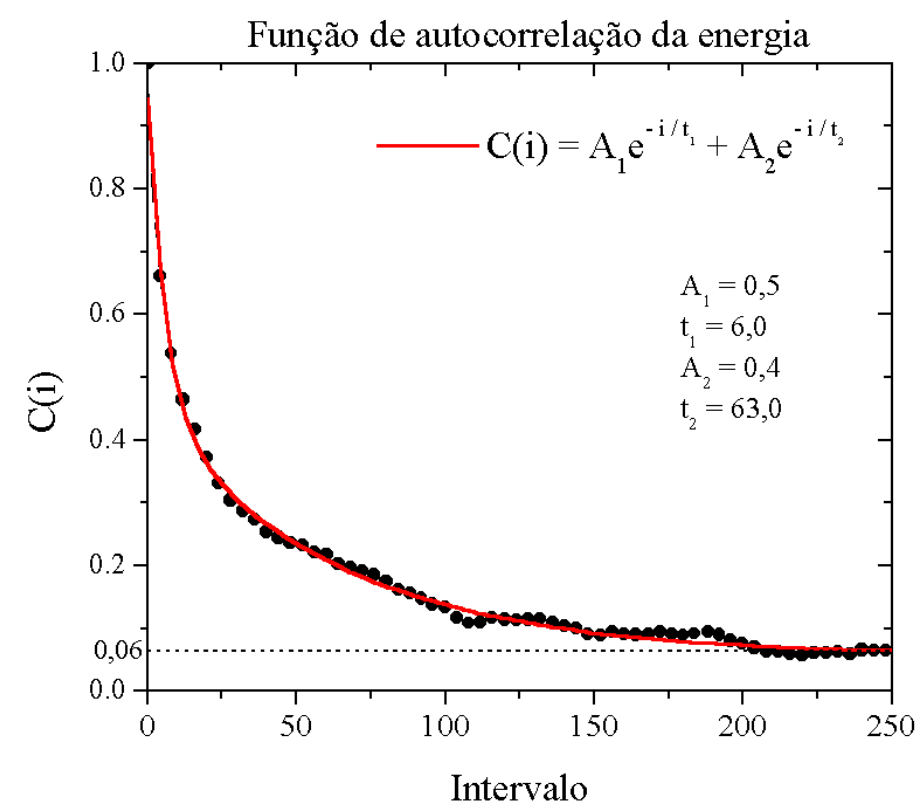

Figura 3.4: Gráfico da função de autocorrelação da energia para as configurações geradas durante a simulação MCM do oxigênio líquido.

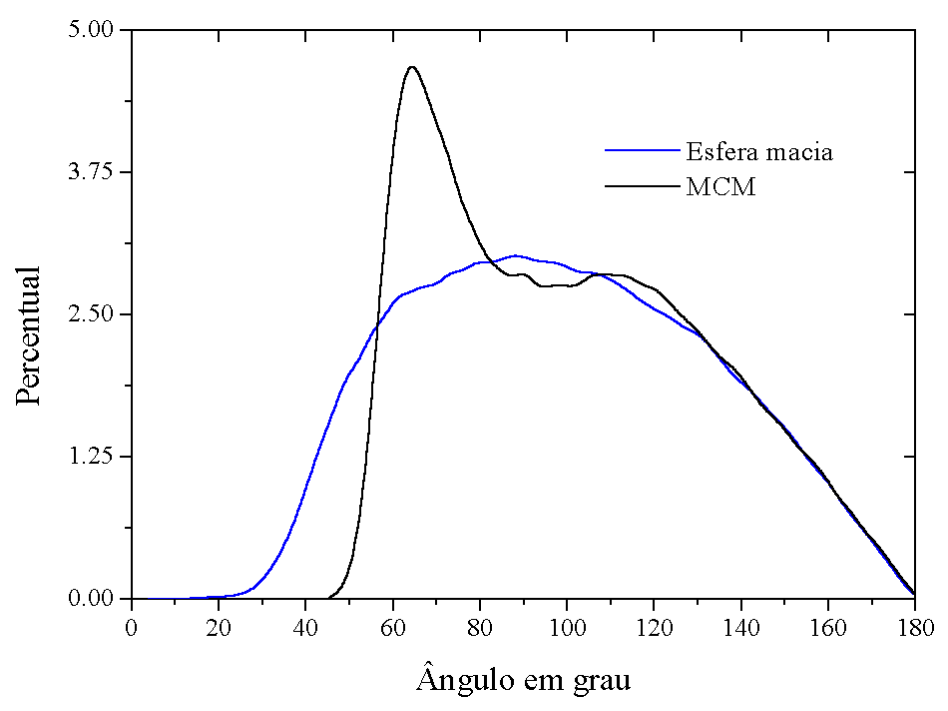

Figura 3.5: Distribuição angular $B_{123}(\theta)$ para o líquido de argônio com $\rho=1,066 \mathrm{~g} / \mathrm{cm}^{3}$ e $T=130 \mathrm{~K}$ obtida pelo método MCM. A curva azul representa a mesma distribuição, porém para um líquido descrito com potencial de esfera quase dura (potencial atrativo nulo e potencial repulsivo proporcional a $r^{-12}$ ). 
de $3,75 \AA$ e que não existem átomos com uma distância inferior a 2,90Å. Assim, supomos que a configuração mais frequente entre três átomos vizinhos de argônio é de um triângulo quase equilátero com distância de aproximadamente $3,75 \AA$ (ver figura 3.6a). Neste caso o ângulo entre os átomos seria de $\sim 60^{\circ}$. Já no caso extremo de maior aproximação entre

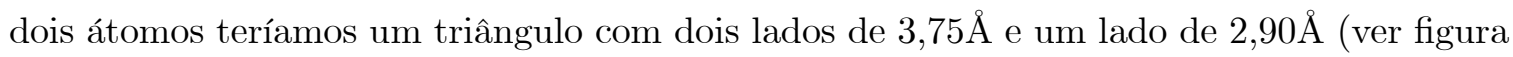
3.6b). Neste caso extremo o ângulo mínimo seria $\sim 45^{\circ}$.

Observe também o comportamento relativo da mesma distribuição quando consideramos um gás ideal com mesma temperatura e densidade. Verificamos que a distribuição é basicamente uniforme, não privilegiando nenhum ângulo.
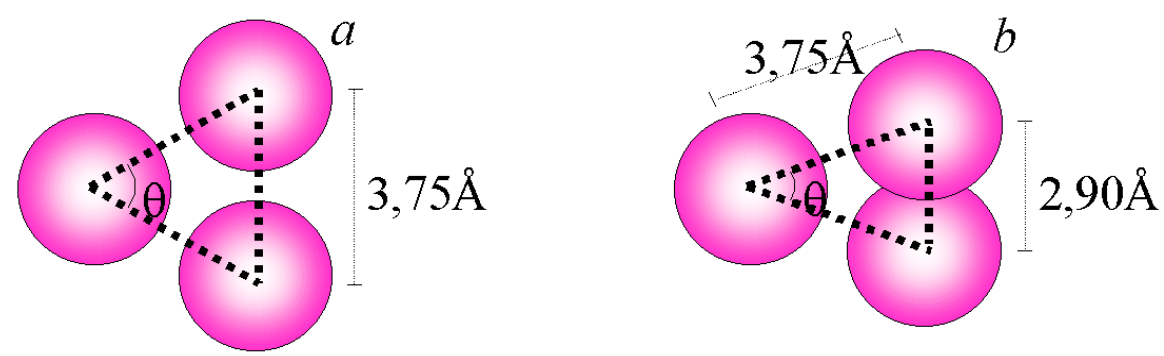

Figura 3.6: ${ }^{a)}$ Posição relativa dos átomos numa configuração mais frequente com a distância entre os átomos de $\sim 3,75 \AA$, gerando um $\theta \sim 60^{\circ}$. $\left.{ }^{b}\right)$ Situação extrema de menor aproximação entre dois átomos, $\sim 2,90 \AA ̊$. Esta configuração indica um ângulo mínimo de $\theta \sim 45^{\circ}$.

\subsection{Simulação Monte Carlo Reverso do argônio}

Na simulação MCR para o argônio utilizamos como dado de entrada a $g(r)$ determinada a partir do método MCM pois assim podemos fazer uma comparação direta entre os resultados obtidos para as duas simulações.

Dois fatores importantes numa simulação Monte Carlo devem ser levados em conta. O primeiro é o deslocamento atômico máximo permitido em cada movimento, $\mathrm{dr}_{\text {máx }}$, que rege a razão entre o número de movimento aceitos e o número de movimento rejeitados e o segundo é o fator $\delta$, que em nossas simulações controlam a qualidade das estruturas geradas. 
Na figura 3.7 podemos verificar como a $g(r)$ varia modificando o valor de $\delta$.

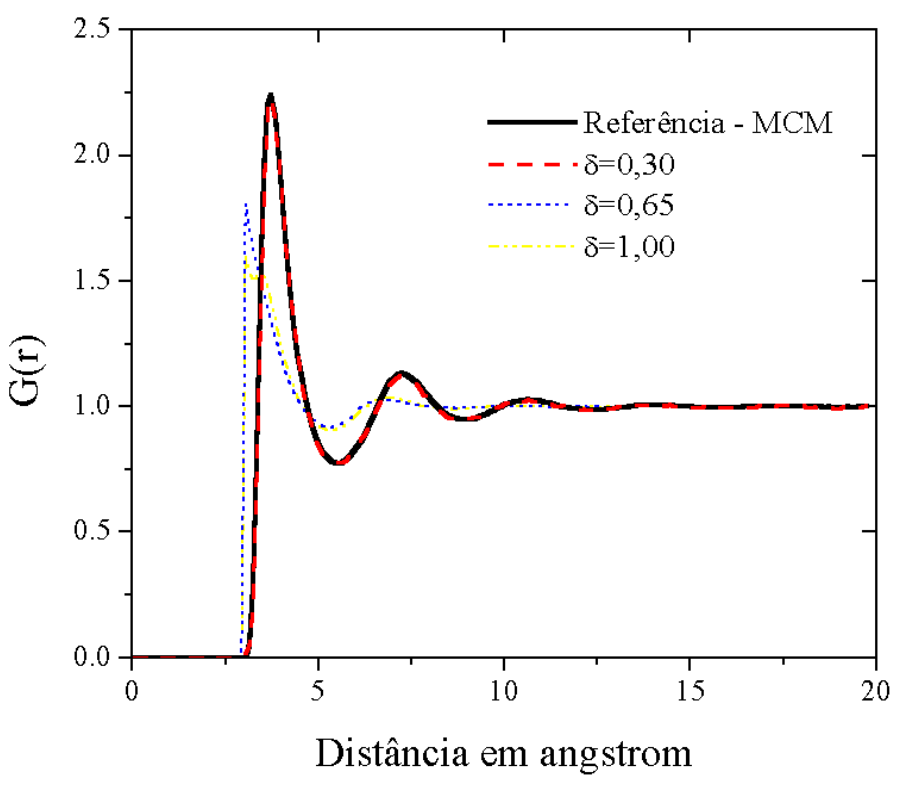

Figura 3.7: A mudança na $g(r)$ de acordo com a variação do critério de convergência $\delta$.

Para o método MCR é comum encontrarmos na literatura textos considerando como uma amplitude máxima razoável para o movimento atômico um valor de $0,3 \AA$. Isto dá uma razão de aceitação e rejeição de $\sim 0,1$ tipicamente quando $\delta$ assume um valor de 0,03 (Mcgreevy, 1988).

Utilizamos o mesmo valor para $\mathrm{dr}_{\text {máx }}$ porém $\operatorname{com} \delta=0,01$ uma vez que desejamos produzir configurações de melhor qualidade. Assim, realizamos uma simulação de 75.000.000 de passos MCR com distância de overlap de 3,0Å. Na figura 3.8 mostramos a concordância entre as funções de distribuição calculadas pelo método MCM e pelo método MCR. Vemos portanto que o método MCR tal qual implementado neste trabalho reproduz muito bem a função distribuição radial de referência.

A função de distribuição angular também foi calculada e podemos verificar que ela é análoga à função calculada pelo método MCM, indicando que os dois métodos caracterizam o líquido de argônio com mesma estrutura local como mostra a figura 3.9. Pusztai e Tóth 


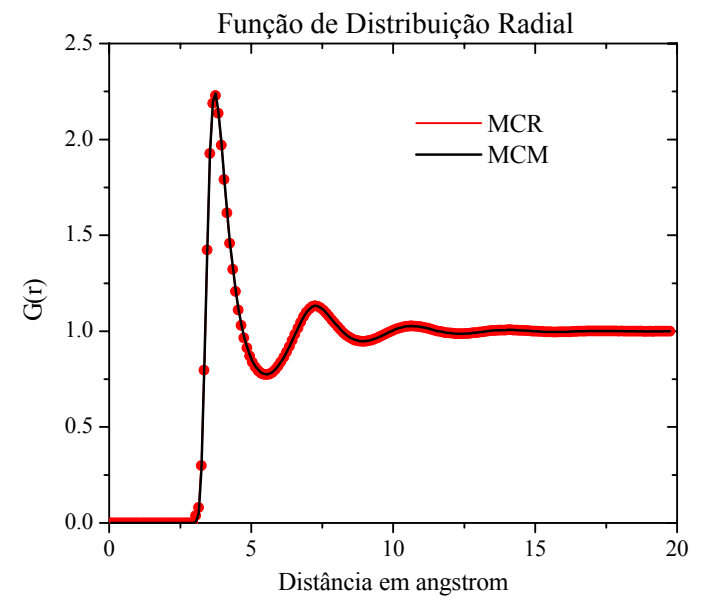

Figura 3.8: Funções de distribuição radial de referência e calculada para o argônio a temperatura de 130K e densidade de $1,066 \mathrm{~g} / \mathrm{cm}^{3}$

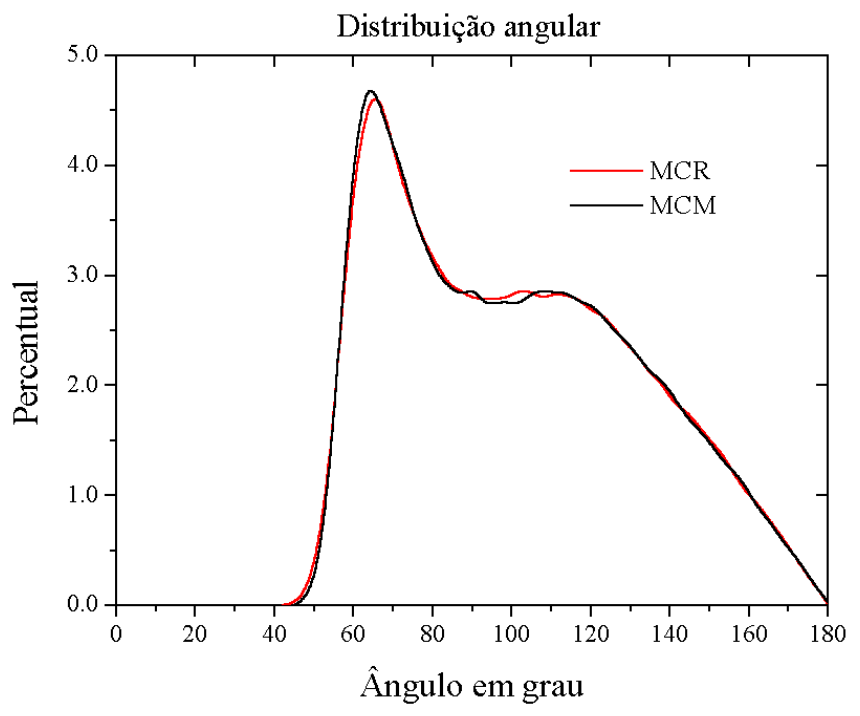

Figura 3.9: Distribuições angular $\mathrm{B}_{123}(\theta)$ para o argônio determinada pelos métodos MCM e MCR. 
(Pusztai, 1991), obtiveram resultados semelhantes para a estrutura deste líquido quando o simulou a uma temperatura de $86,3 \mathrm{~K}$ e densidade de $1,466 \mathrm{~g} / \mathrm{cm}^{3}$.

No intuito de analisar mais características das configurações geradas pelo método MCR, calculamos as propriedades termodinâmicas através das configurações geradas a cada passo da simulação usando o mesmo potencial de interação do MCM. Entretanto, observamos a partir da tabela 3.4 que os valores de tais propriedades variam muito com o critério de convergência, $\delta$, assim como a própria razão de aceitação e rejeição.

O comportamento das propriedades termodinâmicas em função de $\delta$ pode, então, ser analisado a partir da tabela 3.5. Nesta tabela verificamos que a medida que diminuímos o valor de $\delta$, a razão entre movimentos aceitos e rejeitados diminui drasticamente, acarretando uma convergência muito lenta.

Na tentativa de verificar se o baixo percentual de aceitação poderia estar interferindo nos valores médios das propriedades termodinâmicas realizamos novas simulações MCR com os mesmos valores, porém adotando agora um critério de auto-ajuste para a amplitude dos movimentos atômicos, buscando uma razão de aceitação e rejeição de aproximadamente 0,5 . Utilizamos também uma gama maior de valores para $\delta$ de maneira a termos mais detalhes sobre a convergência dos resultados. Entretanto verificamos o mesmo comportamento, as propriedades variam com o valor de $\delta$.

\begin{tabular}{ccccccc}
\hline \hline$\delta$ & $\langle U\rangle / N$ & $10^{3} \times\left\langle c_{V}\right\rangle$ & $\left\langle\gamma_{V}\right\rangle$ & $10^{4} \times\left\langle\kappa_{T}\right\rangle$ & $\left\langle\chi^{2}\right\rangle / n$ & $\langle$ Aceit/Rej $\rangle$ \\
0,005 & $-1,036$ & 3,060 & 2,659 & 1,357 & 0,45 & $\sim 0,1 \%$ \\
0,01 & $-1,026$ & 3,166 & 3,254 & 1,404 & 0,45 & $\sim 12 \%$ \\
0,03 & $-0,964$ & 4,020 & 8,420 & 2,020 & 0,58 & $\sim 54 \%$ \\
0,05 & $-0,886$ & 5,399 & 16,659 & 7,035 & 0,78 & $\sim 64 \%$ \\
& & & & & & \\
MCM & $-1,045$ & 4,15 & 8,5 & 13 & 0,33 & $\sim 50 \%$ \\
Experimento & $-1,015$ & 4,061 & 8,00 & 14,00 & - & - \\
\hline \hline
\end{tabular}

Tabela 3.4: A variação das propriedades termodinâmicas do argônio líquido à temperatura de $130 \mathrm{~K}$ e $\rho=1,066 \mathrm{~g} / \mathrm{cm}^{3}$ com a tolerância $\delta, \operatorname{com~dr}_{m a ́ x}$ mantido fixo em $0,3 \AA$. As simulações foram realizadas no ensamble NVT com um overlap de $3,0 \AA$. Na penúltima coluna $n$ representa o número de pontos da $g(r)$. 


\begin{tabular}{ccccccc}
\hline \hline$\delta$ & $\langle U\rangle / N$ & $10^{3} \times\left\langle c_{V}\right\rangle$ & $\left\langle\gamma_{V}\right\rangle$ & $10^{4} \times\left\langle\kappa_{T}\right\rangle$ & $\left\langle\chi^{2}\right\rangle / N$ & $\left\langle\mathrm{dr}_{\text {máx }}\right\rangle$ \\
0,002 & $-1,038$ & 3,018 & 2,415 & 1,331 & 0,47 & 0,003 \\
0,003 & $-1,038$ & 3,036 & 2,537 & 1,343 & 0,44 & 0,005 \\
0,004 & $-1,038$ & 3,031 & 2,537 & 1,350 & 0,42 & 0,008 \\
0,005 & $-1,036$ & 3,056 & 2,614 & 1,350 & 0,43 & 0,011 \\
0,01 & $-1,026$ & 3,160 & 3,221 & 1,404 & 0,46 & 0,037 \\
0,03 & $-0,974$ & 3,804 & 7,191 & 1,803 & 0,58 & 0,340 \\
0,05 & $-0,886$ & 5,378 & 16,518 & 6,415 & 0,72 & 0,513 \\
& & & & & & \\
MCM & $-1,045$ & 4,15 & 8,5 & 13 & 1,01 & $\sim 0,02$ \\
Experimento & $-1,015$ & 4,061 & 8,00 & 14,00 & - & - \\
\hline \hline
\end{tabular}

Tabela 3.5: A variação das propriedades termodinâmicas do argônio líquido a temperatura de $130 \mathrm{~K}$ com auto-ajuste do $\mathrm{dr}_{m a ́ x}$ para ter uma razão entre o número de movimentos aceitos e o número de movimentos rejeitados em torno 0,5 .

Verificamos ainda, a partir das tabelas 3.4 e 3.5, que a medida que diminuímos o fator $\delta$, os valores das propriedades termodinâmicas diminuem. Como a energia depende apenas das coordenadas atômicas, ou seja das configurações, ela atinge uma convergência a medida que as configurações geram uma $g(r)$ mais próxima da de referência. Entretanto as outras propriedades (calor específico, $c_{V}$; coeficiente de pressão térmica, $\gamma_{V}$ ) vão se tornando cada vez mais mal descritas. Observe que estas duas propriedades dependem, respectivamente da flutuação da energia, $\left\langle\Delta U^{2}\right\rangle$ e da flutuação do primeiro virial, $\left\langle\Delta W^{2}\right\rangle$ e as flutuações dependem basicamente de quanto as configurações se diferenciam da $g(r)$ de referência. No método MCM estas flutuações estão relacionadas com a temperatura, porém no método MCR observamos que elas estão relacionadas com o fator $\delta$. Este efeito pode ser verificado na tabela 3.6 onde observamos a variação da flutuação da energia e do virial. Como o fator $\delta$ não tem significado físico, da forma que tem a temperatura, as simulações MCR não pode descrever propriedades termodinâmicas. Além disso, temos que a distribuição de energia num ensemble canônico deve ser gaussiana (Reif, 1965), ou seja, deve obedecer a expressão abaixo: 


\begin{tabular}{ccccc}
\hline \hline & $\langle U\rangle / N$ & $10^{6}\left\langle\Delta U^{2}\right\rangle$ & $\langle W\rangle$ & $\left\langle\Delta W^{2}\right\rangle$ \\
\hline$\delta=0,003$ & $-1,038$ & 1,96 & -224 & 62 \\
$\delta=0,004$ & $-1,038$ & 2,00 & -223 & 73 \\
$\delta=0,005$ & $-1,038$ & 3,62 & -213 & 77 \\
$\delta=0,01$ & $-1,026$ & 5,97 & -173 & 218 \\
$\delta=0,05$ & $-0,886$ & 80,53 & 585 & 2588 \\
\hline \hline
\end{tabular}

Tabela 3.6: Variação da flutuação da energia e do primeiro virial para três diferentes valores de $\delta$. Mostramos também os respectivos valores para a energia e para o primeiro virial em kcal/mol.

$$
\mathfrak{P}(U)=\frac{S}{\sqrt{2 \pi\left\langle\Delta U^{2}\right\rangle}} \exp \left\{-\frac{\left(U_{i}-\langle U\rangle\right)^{2}}{2\left\langle\Delta U^{2}\right\rangle}\right\}
$$

onde $S$ é a área delimitada pela gaussiana. No entanto, da figura 3.10, podemos observar o comportamento da distribuição de energia a medida que aumentamos $\delta$. Podemos observar em outra escala a deformação da distribuição (perda da forma de gaussiana), o que indica que as configurações atômicas geradas, embora apresentem boa concordância com as propriedades estruturais experimentais não satisfazem a distribuição de Boltzmann. 

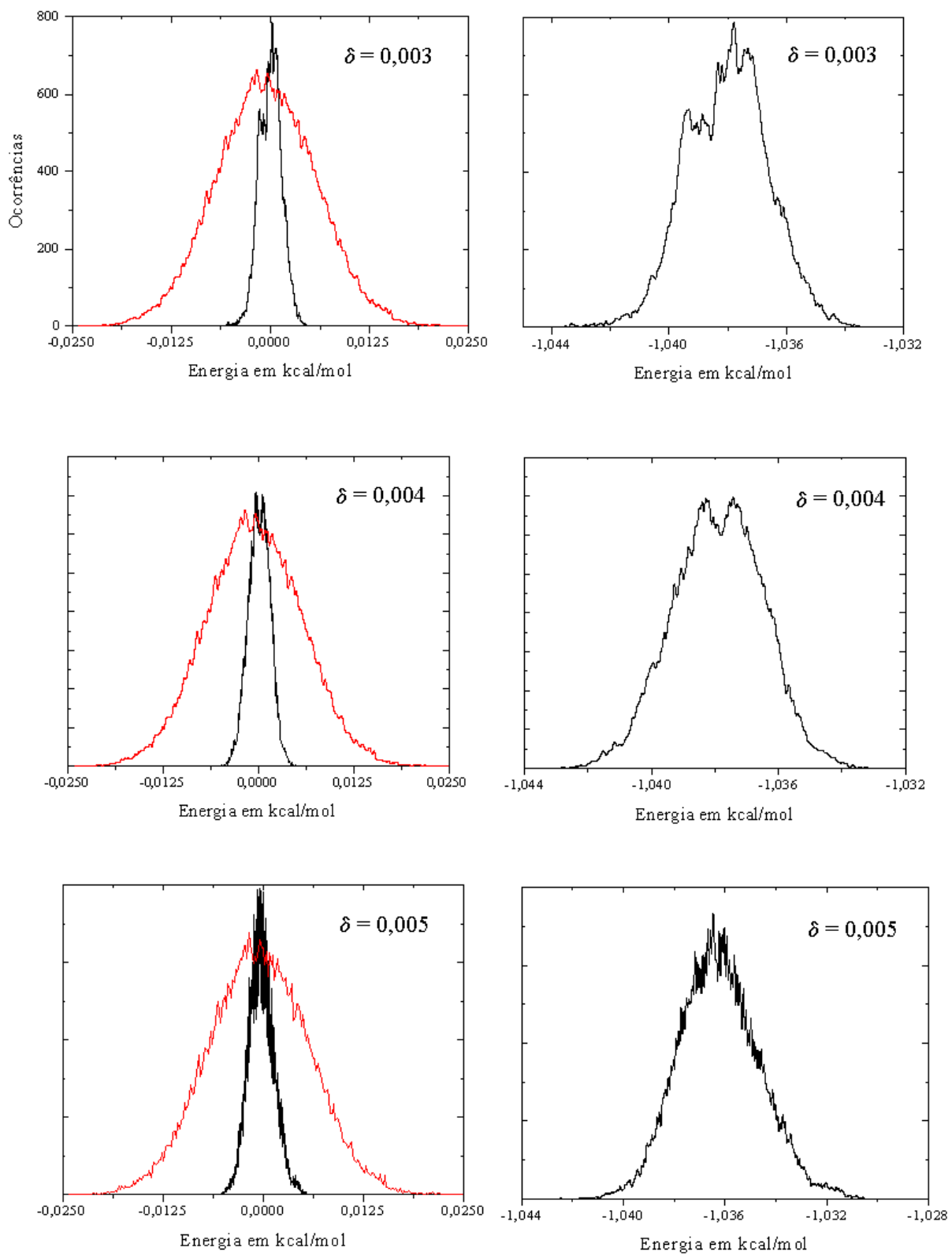

Figura 3.10: O comportamento das distribuições de energias determinadas pelo método MCR (pretas) quando variamos o fator $\delta$ e distribuição canônica de energias (vermelha) para o argônio líquido determinada pelo método MCM. À direita, noutra escala, as mesmas distribuições para os mesmos valores de $\delta$. A escala vertical é a mesma para todos os gráficos. 


\section{Parte 4}

\section{Resultados}

Neste capítulo apresentaremos os resultados obtidos da aplicação do método Monte Carlo Reverso para o oxigênio líquido.

Para continuarmos nossa análise das vantagens e desvantagens deste método, realizamos simulações com o método Monte Carlo Metropolis e fizemos comparações diretas das propriedades estruturais.

Antes de iniciarmos as simulações MCM parametrizamos um potencial (LennardJones) para descrever a interação entre os átomos de oxigênio baseado nas propriedades termodinâmicas deste líquido.

\subsection{Simulação Monte Carlo Metropolis do oxigênio}

Nesta seção apresentaremos as simulações computacionais MCM para o oxigênio líquido. Estas simulações tiveram por objetivo descrever as propriedades termodinâmicas do líquido e ser usadas como parâmetro de comparação para as simulações MCR.

Como uma simulação MCM requer um potencial de interação, partimos inicialmente à procura de um par de parâmetros Lennard-Jones para um potencial que descreva 
bem o oxigênio líquido nas condições desejadas, já que muito pouco se encontra na litereratura sobre o potencial deste sistema. Para isso, utilizamos como ponto de partida os parâmetros de oxigênio encontrados na literatura e dados pela tabela 4.1.

Termalizamos o sistema com cada um destes potenciais no ensemble NPT com o líquido à temperatura de $65 \mathrm{~K}$ e pressão de $0,023 \mathrm{~atm}$. Para cada termalização utilizamos 512 moléculas de $\mathrm{O}_{2}$ e realizamos 5.000.000 passos MCM. Ao final de cada processo coletamos o valor médio da densidade, $\langle\rho\rangle$, no qual o sistema entrou em equilíbrio.

\begin{tabular}{cccc}
\hline \hline $\begin{array}{c}\text { Tipo de parâmetros para o } \\
\text { potencial de Oxigênio }\end{array}$ & $\varepsilon(\mathrm{kcal} / \mathrm{mol})$ & $\sigma(\AA)$ & $\langle\rho\rangle\left(\mathrm{g} / \mathrm{cm}^{3}\right)$ \\
\hline $\mathrm{O}=^{a}$ & 0,21 & 2,96 & 1,546 \\
$\mathrm{OH}^{a}$ & 0,17 & 3,07 & 1,239 \\
$\mathrm{O}^{a}$ & 0,17 & 3,00 & 1,460 \\
$\mathrm{O}^{b}$ & 0,122 & 2,95 & 1,471 \\
$\mathrm{O}^{c}$ & 0,1064 & 2,96 & 1,419 \\
$\mathrm{O}^{c}$ & 0,0985 & 3,14 & 1,168 \\
$\mathrm{H}_{2} \mathrm{O}$ TIP3P & 0,1521 & 3,1506 & 1,246 \\
$\mathrm{H}_{2} \mathrm{O}$ TIP4P & 0,1550 & 3,1537 & 1,247 \\
$\mathrm{H}_{2} \mathrm{O} \mathrm{SPC}{ }^{f}$ & 0,1554 & 3,1656 & 1,233 \\
$\mathrm{CH}_{3} \mathrm{O}{ }^{g}$ & 0,25 & 3,15 & 1,297 \\
$\mathrm{DMSO}^{h}$ & 0,28 & 2,93 & 1,617 \\
\hline \hline
\end{tabular}

Tabela 4.1: Parâmetros do potencial LJ para o oxigênio obtidos da literatura. Simulando o oxigênio líquido a $65 \mathrm{~K}$ e $0,023 \mathrm{~atm}$ obtivemos as densidades mostradas na última coluna. ${ }^{a}$ (Jorgensen, 1988), ${ }^{b}$ (English, 1974), ${ }^{c}$ (Bouanich, 1992) ${ }^{d}$ (Jorgensen, 1983), ${ }^{e}\left(\right.$ Jorgensen, 1985),${ }^{f}$ (Berendsen, 1981), ${ }^{g}($ Jorgensen, 1998), $h_{\text {(Bordwell, 1991) }}$

Da tabela 4.1 verificamos que os potenciais TIP4P e TIP3P foram capazes de gerar a densidade próxima da densidade experimental. Entretanto estes potenciais foram incapazes de descrever as demais propriedades termodinâmicas. Por isso, escolhemos o potencial TIP4P, o que mais se aproximou do valor experimental da densidade, $\rho=1,267 \mathrm{~g} / \mathrm{cm}^{3}$ e a partir dele começamos uma optimização dos parâmetros $\sigma$ e $\varepsilon$ do potencial.

Desta forma, realizamos várias simulações testes com 50.000.000 passos MCM através das quais variamos os valores do parâmetro $\sigma$ do potencial LJ mantendo fixo o parâmetro $\varepsilon$. Variamos, em seguida, os valores do parâmetro $\varepsilon$ mantendo fixo o parâmetro 
$\sigma$. Finalmente, cruzamos os valores de $\sigma$ e $\varepsilon$ para os quais as propriedades termodinâmicas foram mais bem descritas.

A tabela 4.2 mostra os valores experimentais (Frish, 1968; Lide, 1998) comparados com os valores calculados para as propriedades termodinâmicas determinados nas simulações.

\begin{tabular}{|c|c|c|c|c|c|}
\hline Propriedade & Experimental & $\begin{array}{l}\varepsilon=0,0930 \\
\sigma=3,1537\end{array}$ & $\begin{array}{l}\varepsilon=0,1240 \\
\sigma=3,1537\end{array}$ & $\begin{array}{l}\varepsilon=0,1550 \\
\sigma=3,1537\end{array}$ & $\begin{array}{l}\varepsilon=0,1705 \\
\sigma=3,1537\end{array}$ \\
\hline$\rho \mathrm{em} \mathrm{g} / \mathrm{cm}^{3}$ & 1,267 & 1,138 & 1,211 & 1,254 & 1,269 \\
\hline$H \mathrm{em} \mathrm{kcal} / \mathrm{mol}$ & $-1,404^{*}$ & $-1,327$ & $-2,070$ & $-2,818$ & $-3,182$ \\
\hline$\alpha_{p}$ em $10^{3} \times \mathrm{K}^{-1}$ & 18,73 & 19,00 & 18,11 & 17,52 & 17,07 \\
\hline$\kappa_{T}$ em $10^{4} \times \mathrm{atm}^{-1}$ & 1,06 & 1,23 & 0,67 & 0,44 & 0,34 \\
\hline$c_{p} \mathrm{em} \mathrm{cal} / \mathrm{mol} . \mathrm{K}$ & 12,7 & 13,2 & 13,9 & 14,3 & 13,5 \\
\hline Propriedade & Experimental & $\begin{array}{l}\varepsilon=0,1550 \\
\sigma=2,8383\end{array}$ & $\begin{array}{l}\varepsilon=0,1550 \\
\sigma=3,1537\end{array}$ & $\begin{array}{l}\varepsilon=0,1550 \\
\sigma=3,4691\end{array}$ & $\begin{array}{l}\varepsilon=0,1550 \\
\sigma=3,7844\end{array}$ \\
\hline$\rho \mathrm{em} \mathrm{g} / \mathrm{cm}^{3}$ & 1,267 & 1,720 & 1,254 & 0,942 & 0,726 \\
\hline$H \mathrm{em} \mathrm{kcal} / \mathrm{mol}$ & $-1,404^{*}$ & $-2,816$ & $-2,818$ & $-2,816$ & $-2,818$ \\
\hline$\alpha_{p}$ em $10^{3} \times \mathrm{K}^{-1}$ & 18,73 & 17,27 & 17,52 & 17,44 & 17,31 \\
\hline$\kappa_{T}$ em $10^{4} \times \mathrm{atm}^{-1}$ & 1,06 & 0,30 & 0,44 & 0,57 & 0,71 \\
\hline$c_{p} \mathrm{em} \mathrm{cal} / \mathrm{mol} . \mathrm{K}$ & 12,7 & 13,3 & 14,3 & 14,1 & 13,6 \\
\hline
\end{tabular}

Tabela 4.2: Propriedades termodinâmicas do oxigênio líquido a $65 \mathrm{~K}$ e $0,023 \mathrm{~atm}$. Na tabela $\varepsilon$ está dado em kcal $/ \mathrm{mol}$ e $\sigma$ em $\AA$. O asterisco indica que a propriedade foi medida experimentalmente em condições ligeiramente diferentes das condições que usamos na simulação (60K e pressão 0,987atm), (Lide, 1998).

Desta tabela podemos verificar que:

$$
\begin{array}{l|l}
\text { quando } \varepsilon \text { cresce } \rightarrow & \begin{array}{l}
\rho \text { cresce } \\
c_{P} \text { cresce } \\
\kappa \text { diminui } \\
H \text { diminui } \\
\alpha_{P} \text { diminui }
\end{array} \\
\text { quando } \sigma \text { cresce } \rightarrow & \begin{array}{l}
\rho \text { diminui } \\
\kappa \text { cresce } \\
c_{P} \text { não apresenta tendência } \\
H \text { não apresenta tendência } \\
\alpha_{P} \text { não apresenta tendência }
\end{array}
\end{array}
$$

Podemos observar que apenas a densidade, $\rho$, e a compressibilidade isotérmica, $\kappa_{T}$, apre- 
sentam tendências bem definidas quando variamos os parâmetros $\varepsilon$ e $\sigma$ do potencial. Como consequência utilizamos estas duas propriedades para construir superfícies de mapeamento dos parâmetros. Estas superfícies estão mostradas na figura 4.1. Nelas identificamos faixas com valores diferentes para $\rho$ e $\kappa_{T}$. Fazendo a interseção das duas superfícies, podemos restringir um pequeno intervalo de valores dos parâmetros $\varepsilon$ e $\sigma$ que dariam $\rho$ e $\kappa_{T}$ próximos dos valores experimentais $\left(1,267 \mathrm{~g} / \mathrm{cm}^{3}\right.$ e $1,06 \times 10^{-4} \mathrm{~atm}^{-1}$, respectivamente).

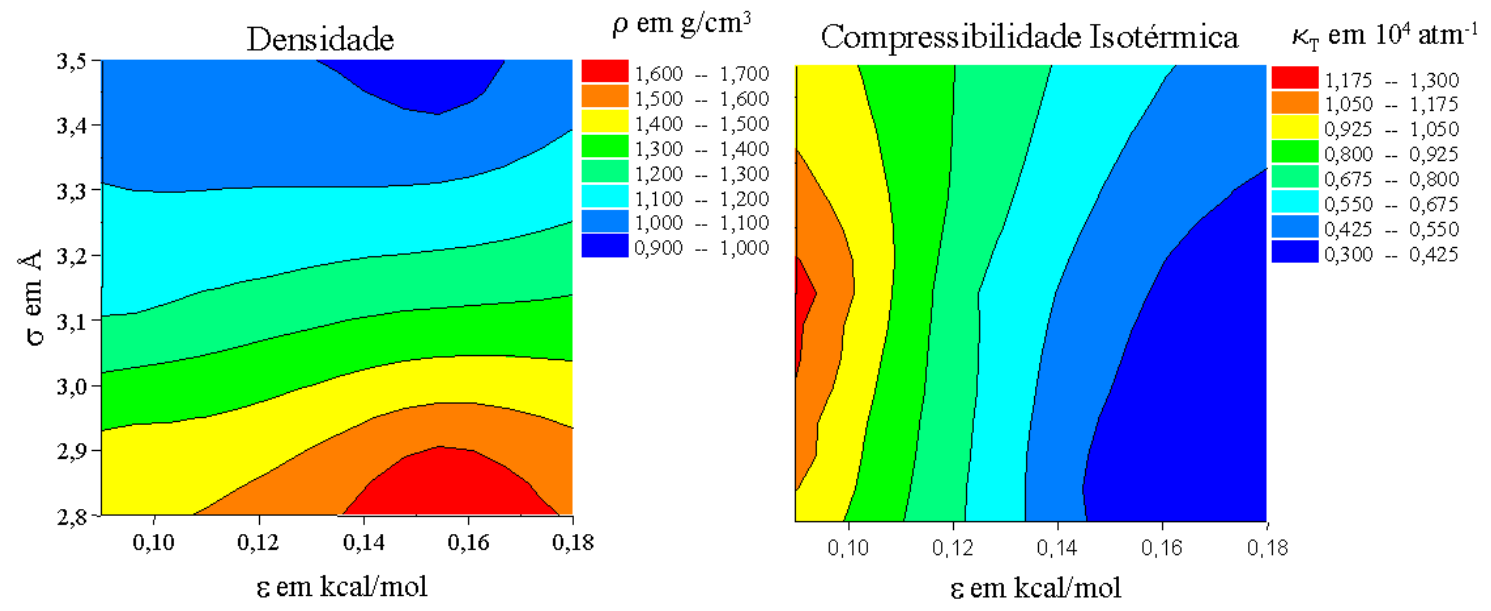

Figura 4.1: Densidade (à esquerda) e compressibilidade isotérmica (à direita) em função dos parâmetros $\sigma$ e $\varepsilon$ do potencial LJ.

Realizamos então novas simulações, cujos resultados são mostrados na tabela 4.3. Melhoramos as superfícies de mapeamento (mostradas na figura 4.1) e encontramos um intervalo de valores $\varepsilon$ e $\sigma$ ainda mais restrito que nos levou aos valores ótimos $\varepsilon=$ $0,0970 \mathrm{kcal} / \mathrm{mol}$ e $\sigma=3,0533 \AA$. Com estes parâmetros otimizados realizamos uma simulação de 75.000 .000 de passos MCM para 512 moléculas de oxigênio a uma temperatura de $65 \mathrm{~K}$ e pressão de $0,023 \mathrm{~atm}$. A tabela 4.4 mostra os parâmetros e todas as propriedades termodinâmicas calculadas. Vemos que estes valores estão em bom acordo com os valores experimentais, já que todas as propriedades diferem menos que $2 \%$ exceto o calor específico que difere pouco mais que $7 \%$. 


\begin{tabular}{|c|c|c|c|c|}
\hline Propriedade & Experimental & $\begin{array}{l}\varepsilon=0,1705 \\
\sigma=3,7844\end{array}$ & $\begin{array}{l}\varepsilon=0,0961 \\
\sigma=2,9818\end{array}$ & $\begin{array}{l}\varepsilon=0,0903 \\
\sigma=2,9233\end{array}$ \\
\hline$\rho \mathrm{em} \mathrm{g} / \mathrm{cm}^{3}$ & 1,267 & 0,7339 & 1,3583 & 1,4177 \\
\hline$H \mathrm{em} \mathrm{kcal} / \mathrm{mol}$ & $-1,404^{*}$ & $-1,203$ & $-1,401$ & $-1,261$ \\
\hline$\alpha_{p}$ em $10^{3} \times \mathrm{K}^{-1}$ & 18,73 & 17,31 & 19,37 & 19,71 \\
\hline$\kappa_{T}$ em $10^{4} \times \mathrm{atm}^{-1}$ & 1,06 & 0,64 & 1,03 & 1,15 \\
\hline$c_{p}$ em cal/mol.K & 12,7 & 14,4 & 14,3 & 14,1 \\
\hline Propriedade & Experimental & $\begin{array}{l}\varepsilon=0,0931 \\
\sigma=2,9800\end{array}$ & $\begin{array}{l}\varepsilon=0,0939 \\
\sigma=2,9533\end{array}$ & $\begin{array}{l}\varepsilon=0,0970 \\
\sigma=3,1020\end{array}$ \\
\hline$\rho \mathrm{em} \mathrm{g} / \mathrm{cm}^{3}$ & 1,267 & 1,3503 & 1,3899 & 1,2091 \\
\hline$H \mathrm{em} \mathrm{kcal} / \mathrm{mol}$ & $-1,404^{*}$ & $-1,330$ & $-1,348$ & $-1,422$ \\
\hline$\alpha_{p}$ em $10^{3} \times \mathrm{K}^{-1}$ & 18,73 & 19,68 & 19,26 & 19,05 \\
\hline$\kappa_{T}$ em $10^{4} \times \mathrm{atm}^{-1}$ & 1,06 & 1,14 & 1,02 & 1,08 \\
\hline$c_{p} \mathrm{em} \mathrm{cal} / \mathrm{mol} . \mathrm{K}$ & 12,7 & 14,6 & 13,70 & 13,70 \\
\hline
\end{tabular}

Tabela 4.3: Propriedades termodinâmicas do líquido de oxigênio à temperatura de $65 \mathrm{~K}$ e pressão de 0,023 atm com os melhores valores de $\sigma(\AA)$ e de $\varepsilon(\mathrm{kcal} / \mathrm{mol})$. O asterisco indica que a propriedade foi medida experimentalmente em condições ligeiramente diferentes das condições que usamos na simulação (60K e pressão 0,987atm), (Lide, 1998).

\begin{tabular}{cccc}
\hline \hline \multirow{2}{*}{ Propriedade } & Unidade & Experimental & $\varepsilon=0,0970$ \\
& & & $\sigma=3,0533$ \\
$\rho$ & $\mathrm{g} / \mathrm{cm}^{3}$ & 1,267 & 1,268 \\
$H$ & $\mathrm{kcal} / \mathrm{mol}^{-1}$ & $-1,404$ & $-1,422$ \\
$\alpha_{p}$ & $10^{3} \times \mathrm{K}^{-1}$ & 18,73 & 19,01 \\
$\kappa_{T}$ & $10^{4} \times \mathrm{atm}^{-1}$ & 1,06 & 1,05 \\
$c_{p}$ & $\mathrm{cal} / \mathrm{mol.K}$ & $12,70^{*}$ & 13,74 \\
\hline \hline
\end{tabular}

Tabela 4.4: Propriedades termodinâmicas do oxigênio líquido a temperatura de $65 \mathrm{~K}$ e pressão de 0,023 atm com os valores ótimos de $\sigma(\AA)$ e de $\varepsilon(\mathrm{kcal} / \mathrm{mol})$. Aqui o asterisco indica que o valor do calor específico não está acrescido do termo vibracional, o qual estimamos ser de $\sim 1 \mathrm{kcal} / \mathrm{mol}$. 


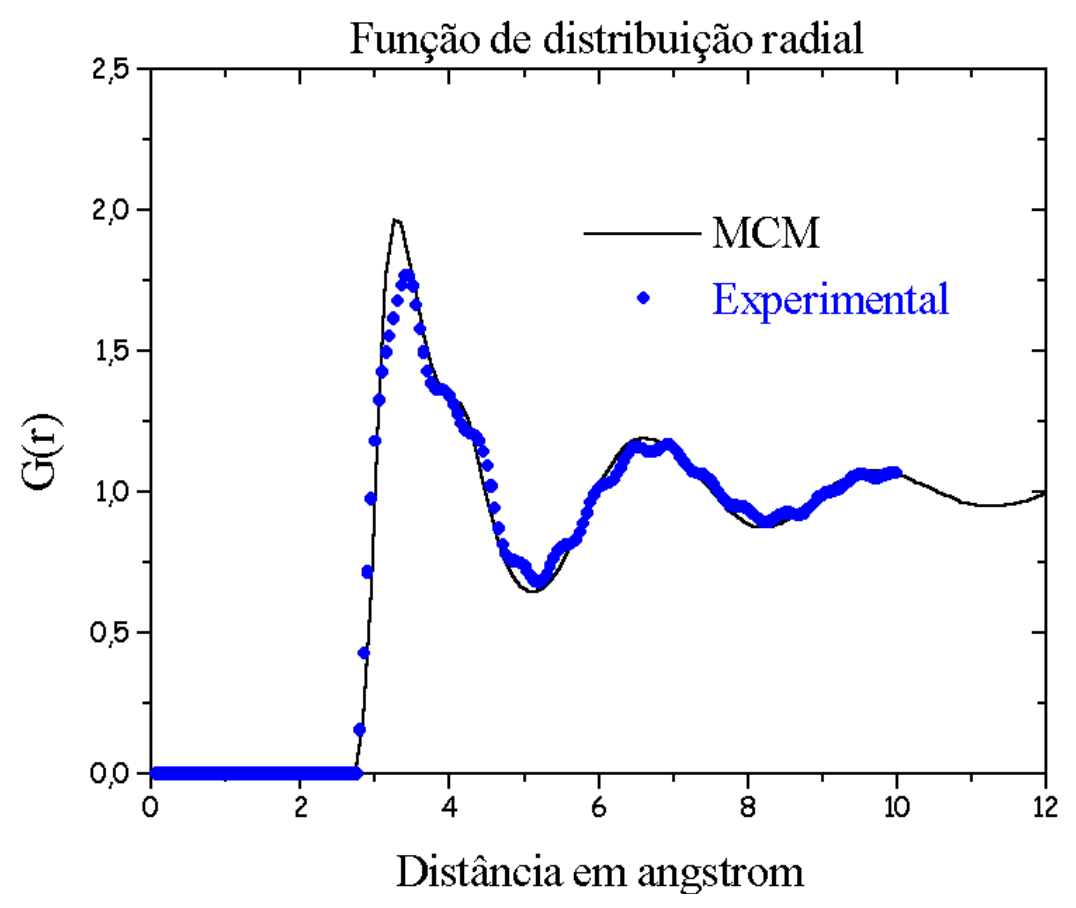

Figura 4.2: Funções de distribuição radial experimental (Frish, 1968) e calculada para o argônio líquido.

Após termos obtidos bons resultados para as propriedades termodinâmicas para o líquido de oxigênio, analisamos as propriedades estruturais. Na figura 4.2, apresentamos as funções de distribuição radial experimental e obtida da simulação MCM com os parâmetros $\varepsilon$ e $\sigma$ ótimos (ver tabela 4.4). Observamos tabela 4.5 que existe uma concordância muito boa entre as duas curvas tanto para os valores dos picos quanto para os números de cordenação.

As estruturas geradas na simulação com os valores ótimos de $\varepsilon$ e $\sigma$ mostrados na tabela 4.4 podem ser analisadas em termos da distribuição de distância e de ângulos entre duas moléculas. Como definido na seção 2.3.3, determinamos um histograma de distâncias de centro de massa das moléculas e também um histograma dos ângulos que as moléculas fazem entre si. Na figura 4.3 temos o histograma de distâncias determinado a partir das estruturas MCM. Vemos que grande parte das moléculas estão distantes aproximadamente $3,57 \AA ̊$. 


\begin{tabular}{|c|c|c|c|c|c|c|}
\cline { 2 - 5 } \multicolumn{1}{c|}{} & \multicolumn{2}{c|}{$1^{\circ}$ pico } & \multicolumn{2}{c|}{$2^{\circ}$ pico } & \multicolumn{1}{c|}{} \\
\cline { 2 - 5 } \multicolumn{1}{c|}{} & máx. & mín. & $\mathrm{N}_{c}$ & máx. & mín. & $\mathrm{N}_{c}$ \\
\hline MCM & $3,30 \AA$ & $5,05 \AA$ & 13 átomos & $6,65 \AA$ & $8,35 \AA$ & 58 átomos \\
\hline Exp & $3,39 \AA$ & $5,20 \AA$ & 13 átomos & $6,70 \AA$ & $8,23 \AA$ & 58 átomos \\
\hline
\end{tabular}

Tabela 4.5: Comparação da posição e dos respectivos números de coordenaçãodos dos picos calculado e experimental (Frish, 1968).

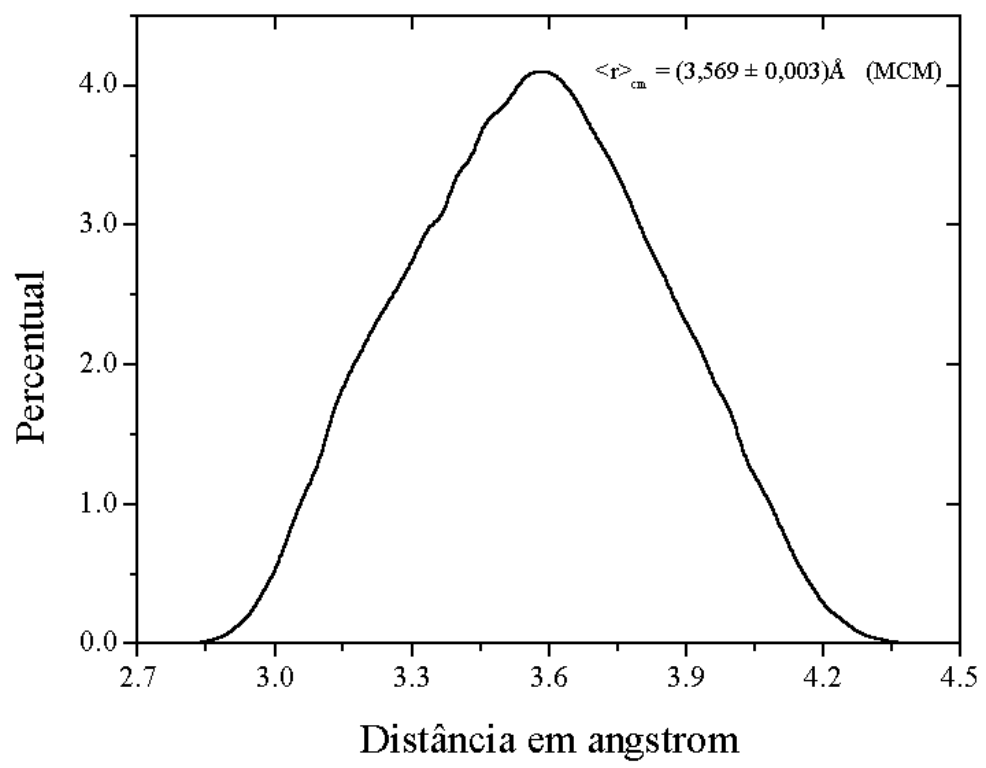

Figura 4.3: Histograma de distâncias de centro de massa das moléculas. A maior ocorrência está a uma distância de aproximadamente $3,57 \AA$.

Baseado nas definições da seção 2.3.3 fizemos uma análise detalhadas das conformações angulares contidas nas estruturas produzidas. Primeiramente utilizamos a distribuição $B(\theta)$. Esta distribuição mostra os ângulos formados pelos dois vetores que unem os centros de massa de uma molécula com as duas outras moléculas mais próximas. Para as estruturas MCM obtivemos a distribuição dada na figura 4.4. Nesta figura podemos observar que a distribuição angular apresentou dois picos, um em torno de $65^{\circ}$ e outro menos elevado em torno de $115^{\circ}$. Observamos que esta distribuição tem um formato semelhante ao obtido para o argônio (figura 3.9), porém para o oxigênio o segundo pico é mais bem definido. Isto sugere que, como esperado, o líquido de oxigênio apresenta estrutura mais 
complexa que a do líquido de argônio.

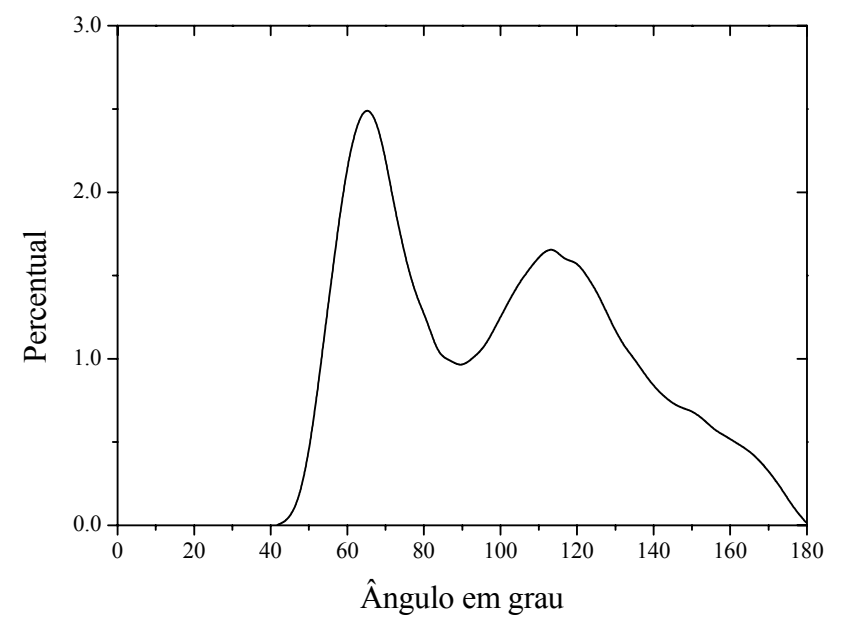

Figura 4.4: Distribuição angular para o líquido de oxigênio calculado da simulação MCM.

A figura 4.5 nos mostra a distribuição dos ângulos $\theta_{1}$ e $\theta_{2}$ nas estruturas analisadas. Podemos observar que existe uma simetria com relação ao plano perpendicular ao eixo z $\left(\theta=90^{\circ}\right)$. Isto se deve as fato dos dois átomos da molécula serem iguais e com isto não ter uma direção definida para o vetor da molécula. Ele pode ser definido como $\mathbf{v}=\mathbf{r}_{01}-\mathbf{r}_{02}$ ou $\mathbf{v}=\mathbf{r}_{02}-\mathbf{r}_{01}$, assim com uma única orientação da molécula $1, \theta_{1}$ pode ser $70^{\circ}$ ou $110^{\circ}$ (figura 4.6) dependendo de como o vetor $\mathbf{v}$ for definido.

Tanto a distribuição para o ângulo $\theta_{1}$ quanto para o ângulo $\theta_{2}$ revelam uma incidência maior em torno de $70^{\circ}$ para z positivo e negativo. Adicionalmente, como esperado, podemos perceber o comportamento semelhante destes ângulos $\theta_{1}$ e $\theta_{2}$. Na figura 4.7 notamos que o ângulo diedro, $\phi$, não tem um valor preferencial, o que indica que não há uma preferência angular entre os planos formados por moléculas vizinhas.

Finalmente podemos fazer uma análise populacional afim de verificarmos o percentual existente de cada conformação; cruz, paralelo deslocado, lado-a-lado, paralelo, tê e 


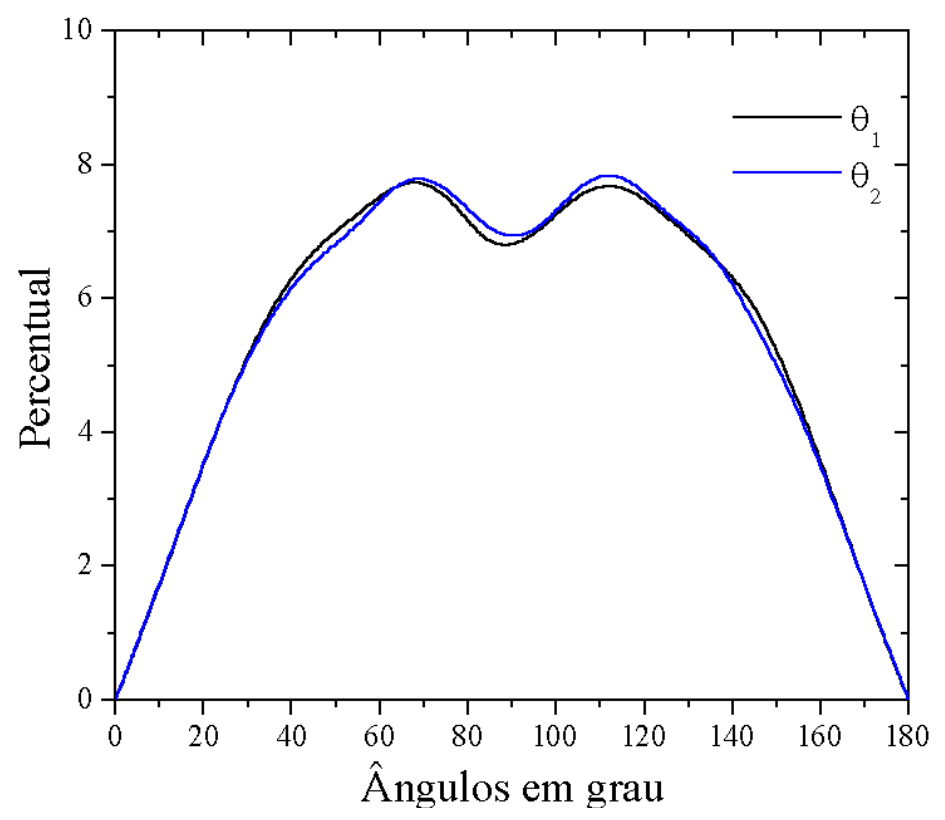

Figura 4.5: Os ângulos $\theta_{1}$ e $\theta_{2}$ e seus percentuais de ocorrência nas estruturas MCM.
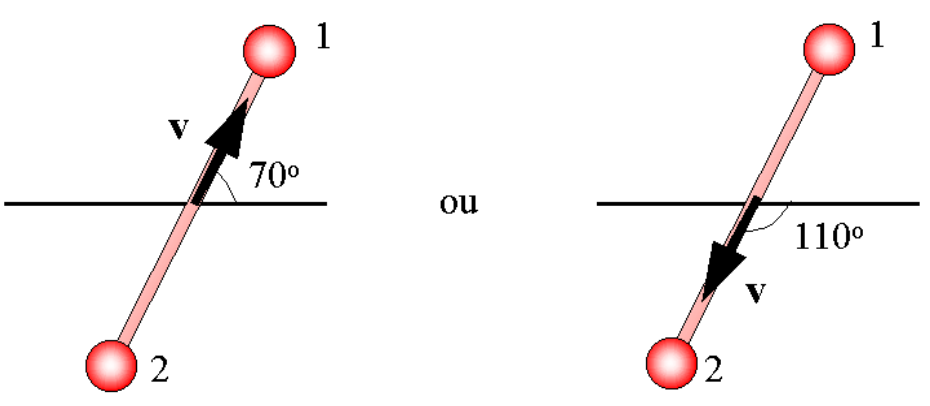

Figura 4.6: Simetria do ângulo $\theta$ em relação ao plano perpendicular ao eixo z, devido a equivalência dos átomos 1 e 2 na moléula de $\mathrm{O}_{2}$. No nosso programa a definição do vetor $\mathbf{v}$ de cada molécula é aleatória. 
vê, definidas na tabela 2.1 .

Na figura 4.8 temos o número de ocorrências para cada conformação. Em termos percentuais temos 4,6\% para a configuração vê; 4,5\% para a configuração paralelo deslocado; $3,7 \%$ para a configuração tê; $2,4 \%$ para a configuração paralelo; $1,8 \%$ para a configuração cruz e 0,5\% para configuração lado-a-lado. Este percentual se refere a um total de 153.600 dímeros analisados. Somando todos os percentuais observamos que somente 17,5\% das conformações estão classificadas nos grupos que consideramos. Portanto a maioria, 82,5\%, das conformações não apresenta preferência conformacional. Acreditamos que isto está relacionado com o comportamentodo uniforme do ângulo diedro $\phi$ mostrado na figura 4.7.

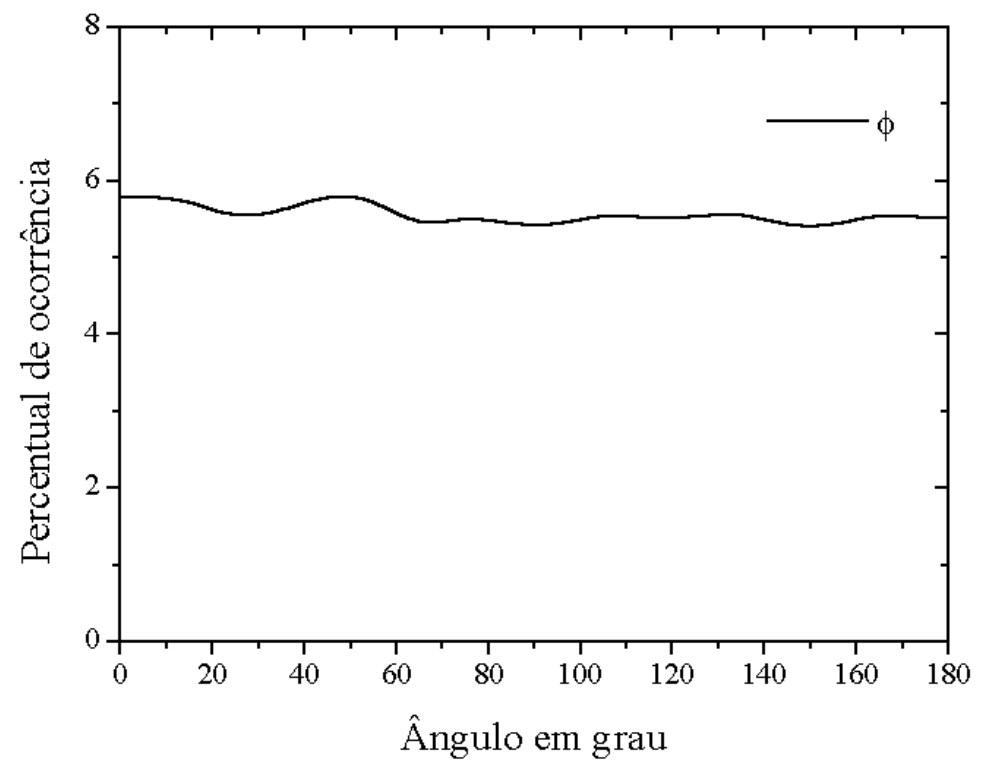

Figura 4.7: Distribuição do ângulo diedro para as estruturas MCM. 


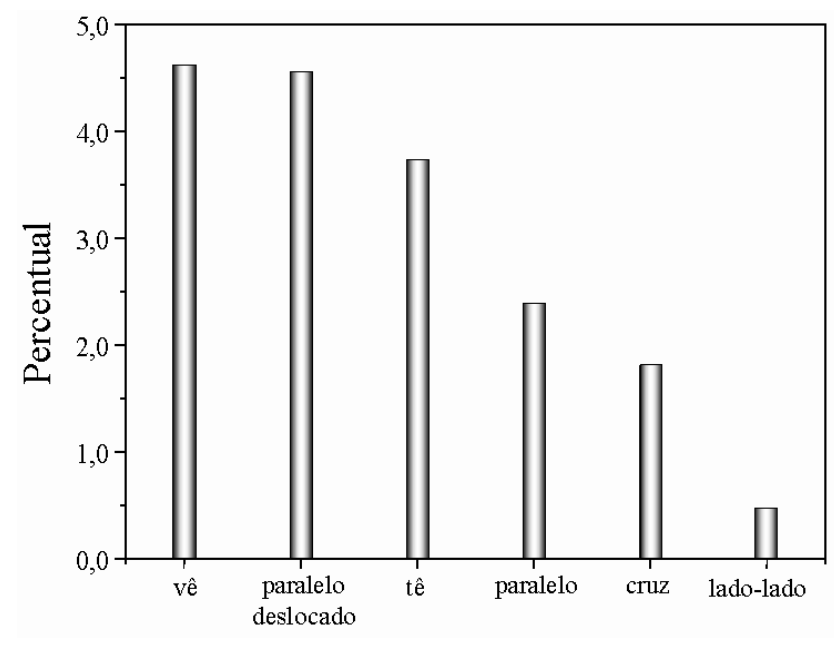

Figura 4.8: Percentual de ocorrência para cada tipo de conformação analisada.

\subsection{Simulação Monte Carlo Reverso do oxigênio (atômico)}

Numa primeira abordagem, tentamos simular o oxigênio líquido via simulações MCR partindo de átomos soltos. Realizamos então uma simulação de 50.000.000 de passos no ensemble NVT com 1000 átomos a uma temperatura de $65 \mathrm{~K}$, densidade de $1,267 \mathrm{~g} / \mathrm{cm}^{3}$ e $\delta=0,03$. A $g(r)$ utilizada como dado de entrada foi a calculada pelo método MCM. Impomos a condição de overlap de que cada átomo não poderia se ligar com outro por uma distância menor que 1,23Å. Vemos pela figura $4.9 a$ que o método MCR reproduz muito bem a função de distribuição radial partindo simplesmente de uma estrutura em que os átomos estão soltos.

Desta simulação retiramos 210 configurações para análises. Observamos contudo (figura 4.9b) que as estruturas geradas possuem características não físicas. Vemos que a maioria dos átomos, cerca de $80 \%$ não faz ligações, enquanto somente $16 \%$ formam moléculas diatômicas. Além disso existe uma quantidade pequena de aglomerados com 3 e 4 átomos. Este padrão não é o esperado para o oxigênio líquido, pois os experimentos mostram 

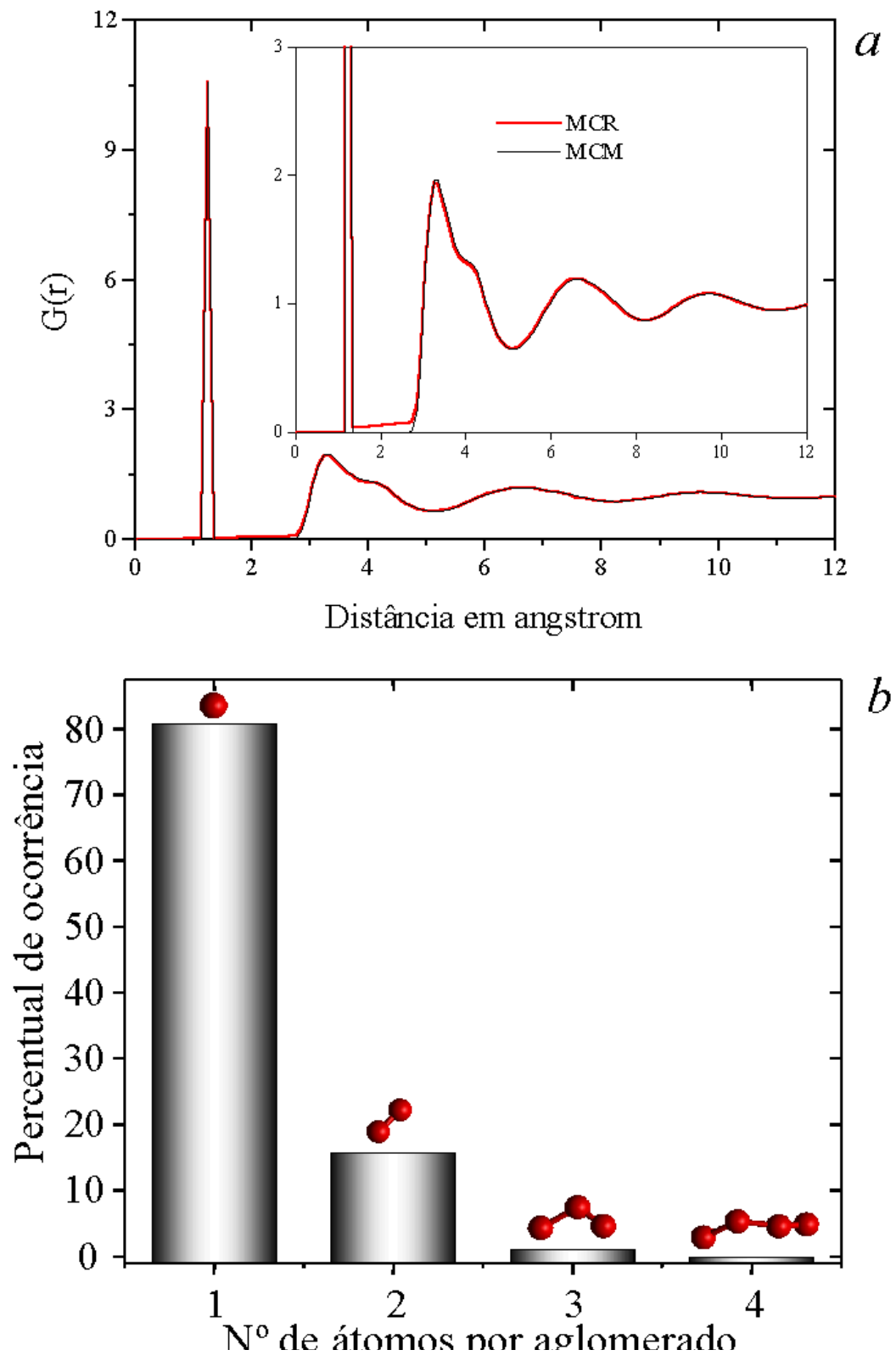

Figura 4.9: ${ }^{a)}$ A função de distribuição radial para o líquido de oxigênio simulado a partir de 1000 átomos a uma tempreatura de $65 \mathrm{~K}$ e densidade de $1,267 \mathrm{~g} / \mathrm{cm}^{3} .{ }^{b)} \mathrm{O}$ percentual de ocorrência para cada aglomerado de átomos. 
que este líquido possui forte caráter molecular, e que os átomos de oxigênio tendem a se ligar covalentemente aos pares. Assim os aglomerados com número ímpar de átomos são improváveis para este sistema nestas condições.

\subsection{Simulação Monte Carlo Reverso do oxigênio (molecular)}

Para esta simulação MCR partimos de uma configuração ordenada de 512 moléculas à temperatura de $65 \mathrm{~K}$, densidade de $1,267 \mathrm{~g} / \mathrm{cm}^{3}$ e $\delta=0,01$ no ensemble NVT.

Realizamos uma simulação de 75.000.000 passos MCR com uma distância de overlap de 2,75A. Desta simulação retiramos 300 configurações descorrelacionadas para análise e estatística.

Analisamos as estruturas, de forma análoga à análise feita para o caso MCM. Na figura 4.10 observamos a boa concordância entre as $g(r)^{s}$ calculadas pelos métodos MCM e MCR. O histograma de distâncias entre as moléculas é dado na figura 4.11. Este gráfico

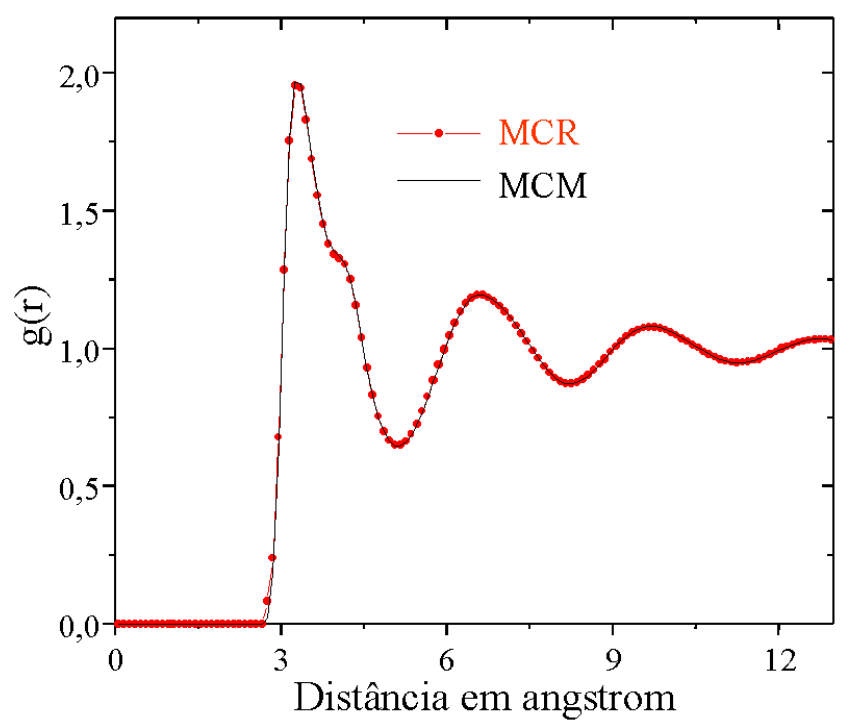

Figura 4.10: Função de distribuição radial para o oxigênio líquido calculadas pelos métodos MCM e MCR.

revela um comportamento análogo ao caso MCM, onde as distâncias de centro de massa 
das moléculas se distribuem em torno de $3,55 \AA$.

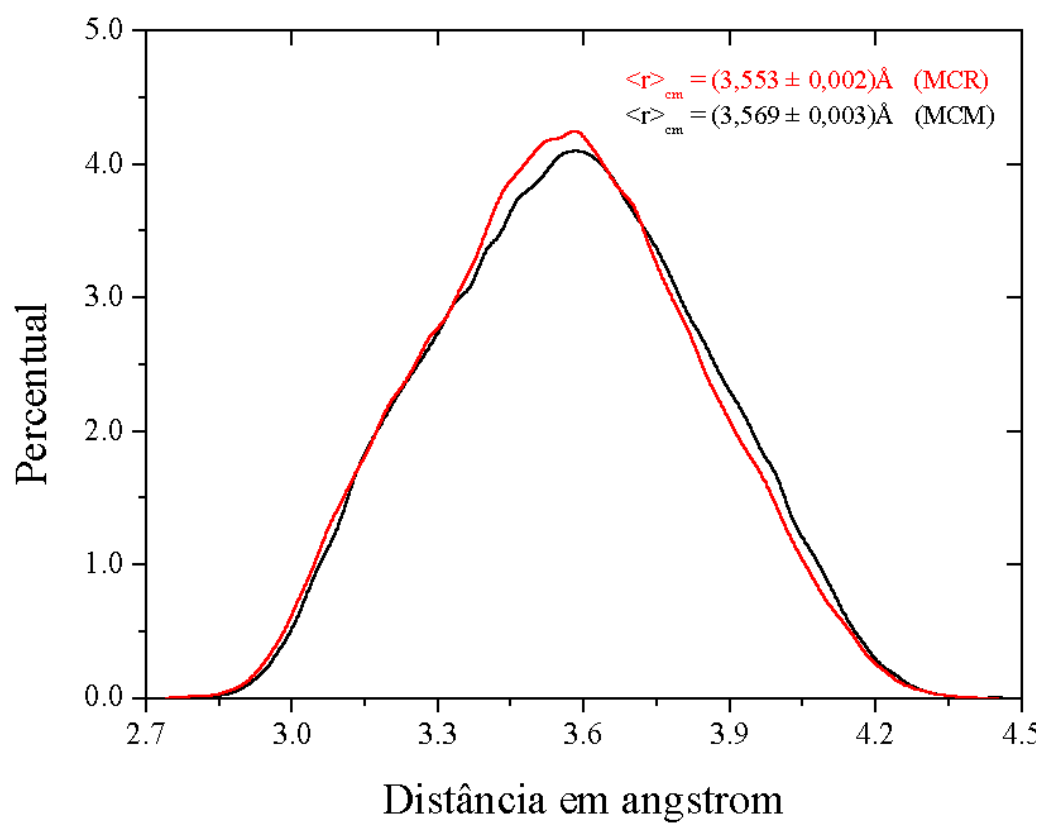

Figura 4.11: Histograma de distâncias relativas à menor distância entre as moléculas.

Assim como na seção anterior fizemos também uma análise das conformações angulares apresentadas pelas configurações produzidas pelo MCR. Na figura 4.12 mostramos a distribuição angular. Aqui vemos um comportamento semelhante com o apresentado pelo MCM. Um pico mais alto em torno de $65^{\circ}$ e um menor em torno de $115^{\circ}$.

Já os ângulos $\theta_{1}$ e $\theta_{2}$ se distribuíram de forma também análoga à sua correspondente distribuição pelo método MCM, tendo um valor máximo de ocorrência em torno de $70^{\circ}$. O ângulo $\phi$ também manteve o mesmo comportamento, ou seja, todos os ângulos foram encontrados com a mesma probabilidade. Na figura 4.13, mostramos a boa concordância entre as distribuições do ângulo $\theta_{2}$ para os dois métodos.

A análise populacional também foi feita para as estruturas MCR, na figura 4.14 temos este histograma. Os valores percentuais para cada conformação são os seguintes: 4,9\% para a configuração vê; $4,7 \%$ para a configuração paralelo deslocado; $3,7 \%$ para a 


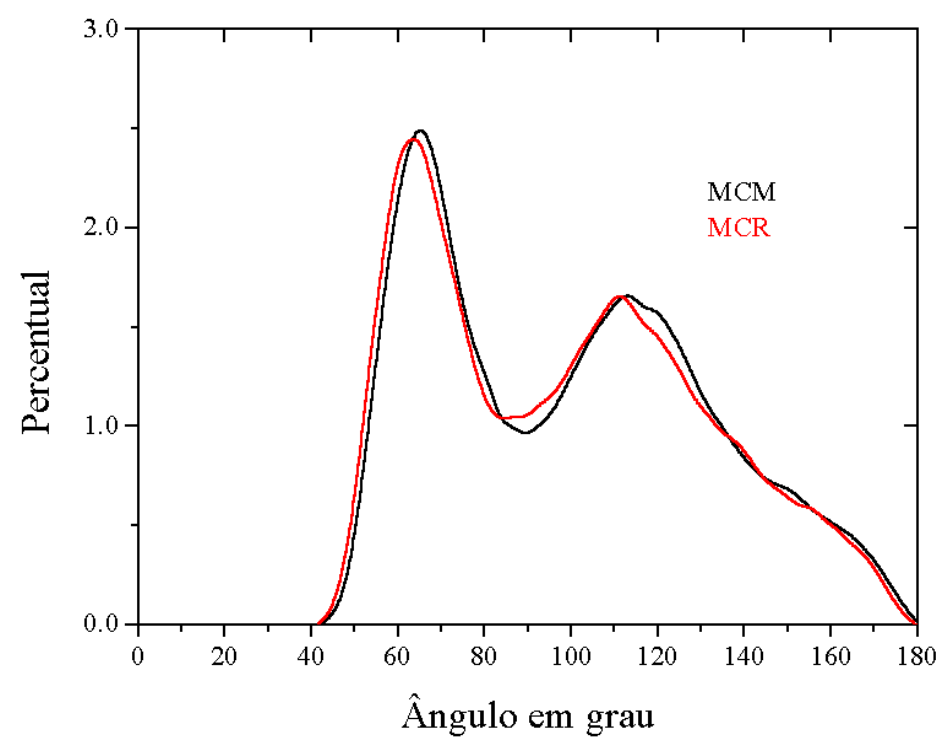

Figura 4.12: Distribuição angular total para as estruturas geradas pelo MCR.

configuração tê; $2,2 \%$ para a configuração paralelo; $1,7 \%$ para configuração cruz e $0,5 \%$ para configuração lado-a-lado. Este percentual se refere a um total de 153.600 configurações analisadas. Assim como no método MCM a maioria, $82,3 \%$, das conformações obtidas pelo método MCR não apresenta preferência conformacional.

Após a análise e comparação dos resultados da simulação do oxigênio líquido observamos dois comportamentos do método MCR. Primeiro, iniciando a simulação com átomos soltos ou moléculas diatômicas observamos (figuras 4.8a e 4.9) que ambos descrevem muito bem a $g(r)$ de referência, porém geram estruturas bem diferentes. Isto nos leva a discussão na literatura sobre a unicidade das configurações geradas no método MCR. Este é um ponto ainda polêmico e muitos autores (Pusztai, 1991) apresentam argumentos e resultados afirmando a unicidade, enquanto que outros (Jedlovszky, 1996) afirmam a não unicidade das configurações geradas pelo método. Neste trabalho com base nos resultados obtidos para o oxigênio verificamos a não unicidade das configurações caso a simulação inicie com moléculas ou átomos soltos. Por outro lado observamos também que independentemente 


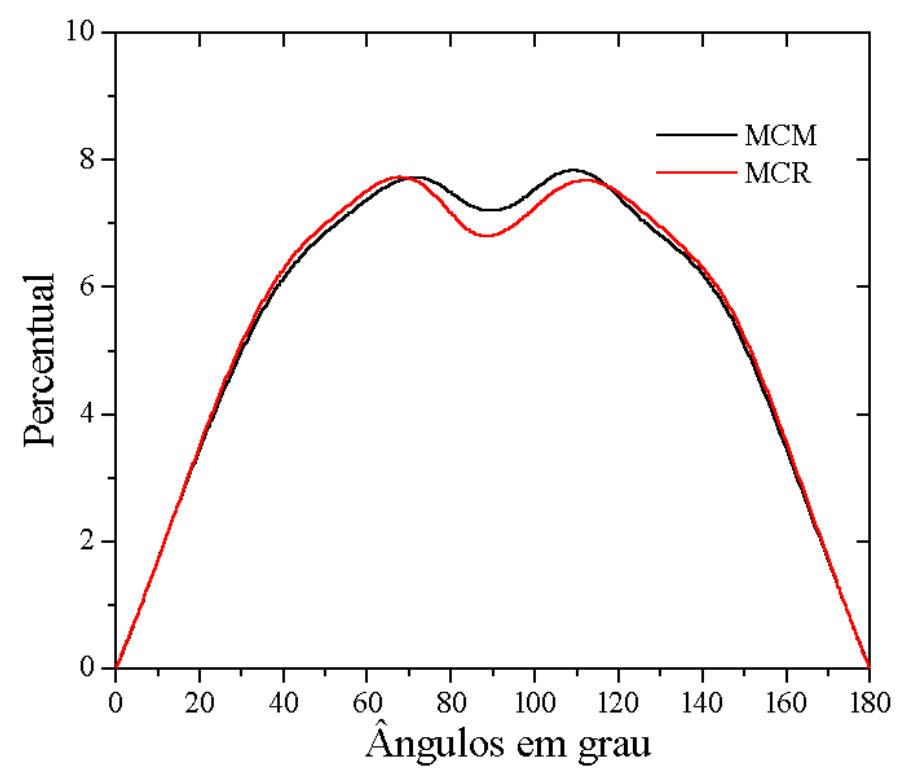

Figura 4.13: Comparação entre as distribuições para o ângulo $\theta_{2}$ pelos dois métodos utilizados.

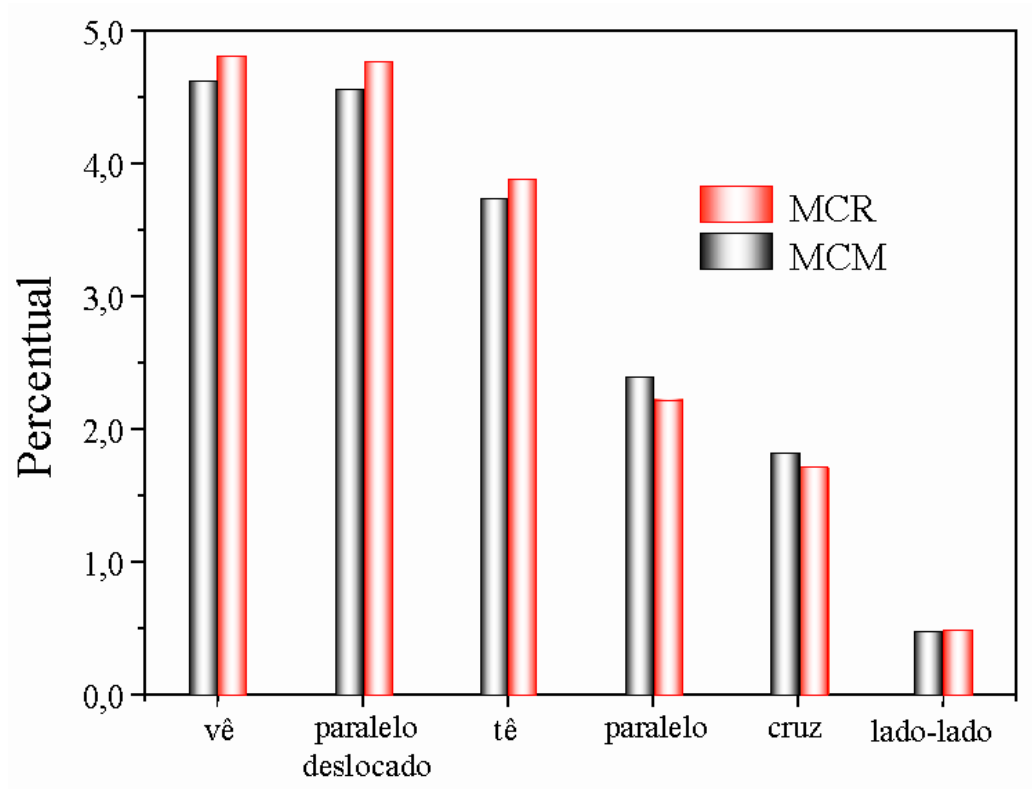

Figura 4.14: Percentual de ocorrência para cada tipo de conformação analisada. 
da configuração inicial, as simulações do oxigênio molecular com o método MCR resultam sempre nas mesmas distribuições das propriedades estruturais $g(r), B(\theta), \theta_{1}, \theta_{2}$ e $\phi$.

O segundo comportamento que observamos é a boa concordância de todas as propriedades estruturais quando comparadas às obtidas para o MCM. O que nos leva a concluir que as estruturas geradas com os dois métodos, MCM e MCR, são equivalentes. 


\section{Parte 5}

\section{Conclusões e Perspectivas}

Neste trabalho propusemos a implementar e aplicar o método Monte Carlo Reverso para sistemas líquidos homogêneos, comparando com os resultados obtidos pelo método Monte Carlo Metropolis. Desenvolvemos para tal fim um código computacional e o aplicamos para dois sitemas líquidos distintos: o argônio líquido que é um líquido atômico amplamente conhecido por métodos teóricos e experimentais, consistindo portanto num sistema teste, e o oxigênio líquido um sistema mais complexo por ser diatômico que foi a aplicação principal deste trabalho.

Numa primeira abordagem, realizamos simulações MCM para o argônio líquido revelando o comportamento termodinâmico do sistema e fornecendo resultados estruturais para ser utilizados como dados de entrada para as simulações MCR. As propriedades termodinâmicas obtidas via simulações MCM (tabela 3.2), comparativamente aos valores experimentais variaram, pouco mais que 5,5\% (compressibilidade isotérmica).

A função de distribuição radial MCM (figura 3.3) também está em bom acordo com a experimental como discutido no capítulo 3. Sendo assim esta $g(r)$ foi utilizada como dado de entrada para as simulações MCR feitas para este sistema de forma que pudemos comparar os resultados MCM e MCR. 
A qualidade das estruturas produzidas pelas simulações MCR dependeram do fator $\delta$, que o fizemos variar nas nossas simulações de 0,05 até 0,002 . Observamos que a qualidade das estruturas saturava para $\delta=0,03$ embora nossas estruturas tenham sido produzidas com $\delta=0,01$ dando uma razão de aproximadamente 0,1 entre movimentos aceitos e movimentos rejeitados.

Através das estruturas geradas pelo MCR e do potencial de interação atômico utilizado no MCM, analisamos o comportamento termodinâmico do sistema simulado pelo MCR. Verificamos que as propriedades termodinâmicas variam muito a medida que modificamos o valor de $\delta$ (tabelas 3.4 e 3.5). Assim podemos manipular as propriedades termodinâmicas do sistema apenas variando $\delta$, o que é inconsistente com a teoria termodinâmica. Concluímos portanto que o método MCR não descreve o comportamento termodinâmico dos sistemas físicos.

Quanto as propriedades estruturais analisamos a distribuição de distâncias entre os centros de massa de moléculas vizinhas (figura 4.10), a distribuição angular entre moléculas vizinhas (figuras 3.9 e 4.11), a distribuição de conformações locais (figura 4.13). Com base nesse resultado concluímos que as estruturas produzidas pelo método MCM e pelo MCR são equivalentes tanto na suas distribuições totais quanto nas conformações locais, de forma que o método é robusto na produção de configurações embora não possa descrever as propriedades termodinâmicas do sistema.

Adicionalmente, analisando os resultados obtidos para a simulação de oxigênio com átomos soltos ou moléculas diatômicas, concluímos que para descrever líquidos moleculares é necessário iniciar a simulação com as moléculas em suas geometrias otimizadas, pois caso contrário não serão capazes de se juntar de forma fisicamente adequada.

Para trabalhos futuros pretendemos estender o projeto para o estudo de líquidos com moléculas maiores, como o benzeno por exemplo. Por outro lado, investigaremos também a possibilidade de produzir estruturas para o estudo de propriedades eletrônicas e de efeitos de solventes através de cálculos quânticos. 


\section{Referências}

Achahbar A., J. Marro; "Phase-Transitions in a Driven Lattice-Gas in 2 Planes", $J$. Stat. Phys., 781493 (1995).

Allen, M. P. and D. J. Tildesley; Computer Simulation of Liquids, Clarendon Press, Oxford (1987).

Andreani, C., J. C. Dore and F. P. Ricci; "Structural characterization of diatomic fluids by diffraction studies", Rep. Prog. Phys., 54731 (1991).

Barker, J. A. and D. Henderson; "What is Liquid - Understanding States of Matter", Rev. Mod. Phys., 48587 (1976).

Berendsen, H. J. C., J. P. M. Postma, W. F. von Gunsteren and J. Hermans; Intermolecular Forces, B. Pullmam (1981).

Blair, J. T., K. K. Jespersen and R. M. Levy; "Solvent Effects on Optical Absorption Spectra: The ${ }^{1} A_{1} \longrightarrow{ }^{1} A_{2}$ Transition of Formaldehyde in Water", J. Am. Chem. Soc., 111 $6948(1989)$.

Bordwell, F.G. T. Gallagher and X. M. Zhang; "Donor-Acceptor Effects on the Stability of Radicals Derived from Alpha-Diakilamino Ketones", J. Am. Chem. Soc., 1133495 (1991).

Briesmeister, J. F., "MCNP-A General Monte Carlo N-Particle Transport Code, Version 4A", Los Alamos National Laboratory, Los Alamos NM, (1993).

Calvo, M., F. Montoya and M. Dzugutov; "Three-Dimensional Characterization of 
Models Representing the Structure of Liquid and Amorphous Alloys", J. Non-Cryst. Sol., 156, 89 (1993).

Cheung, P. S. Y.; "On the calculation of specific heats, thermal pressure coefficients and compressibilities in molecular dynamics simulations", Mol. Phys., 33 519, (1977).

Coutinho K. and S. Canuto, DICE: A Monte Carlo Program for Molecular Liquid Simulation, University of São Paulo, Brazil.

Coutinho, K.; Modelo Discreto de Solvente. Solvatocromismo no Espectro de Absorção Molecular, Tese de Doutorado, IFUSP, São Paulo, 1997.

Coutinho K.; S. Canuto and M. C. Zerner; "A Monte Carlo-Quantum Mechanics Study of the Solvatochromic Shifts of the Lowest Transition of Benzene", J. Chem. Phys., 112 $9874(2000)$

Dragovitsch, P. S. L. and M. Burbank, "Intl. Conf. on Monte Carlo Simulation in High Energy and Nuclear Physics", World Scientific Pub. (1994).

Elliott, S. R.; Physics of Amorphous Material, 2nd ed., New York, Longman Scientific (1990).

English, C. A. and J. A. Venables, "The structure of diatomic molecular solids", Proc. R. Soc. Lond. A. 34057 (1974).

Frisch, H. L., and Z. W.; Salsburg; Simple Dense Fluids, Academic Press, New York, (1968).

Gould, H. and J. Tobochnik; An Introduciton to Computer Simulation Methods, AddisonWesley (1988).

Guinier, A., G. Fournet, C. B. Walkel and K. L. Yudowitch; Small Angle Scattering of X-Ray, Wiley, New York (1995).

Gurman, S. J., and R. L. McGreevy; "Reverse Monte Carlo Simulation for the Analysis of EXAFS Data", J. Phys. Condens. Matter, 2, 9463 (1990).

Howe, M. A., R. L. McGreevy, L. Pusztai and I. Borzsák; "Determination of Three Body Correlations in Simple Liquids by RMC Modelling of Diffraction Data. II. Elemental 
Liquids", Phys. Chem. Liq., 25, 205 (1970).

Howe, M. A.; "The Structure of Liquid Copper Selenide", Phys. B, 160, 170 (1989a).

Howe, M. A.; "Orientational Correlations in the Liquids Halogens", Mol. Phys., 69, $161(1989 b)$.

Jedlovszky, P., I. Bakó and G. Pálinkás; "Reverse Monte Carlo Simulation of Liquid Water", Chem. Phys. Let., 221, 183 (1994).

Jedlovszky, P., I. Bakó, G. Pálinkás and J. C. Dore; "Structural Investigation of Liquid Formic Acid X-Ray and Neutron Diffraction, and Reverse Monte Carlo Study", Mol. Phys., 86, 87 (1995).

Jedlovszky, P., I. Bakó, G. Pálinkás, T. Radnai and A. K. Soper; "Investigation of the Uniqueness of the Reverse Monte Carlo Method: Studies on Liquid Water", J. Chem. Phys., 105, 245 (1996).

Jorgensen, W. L., J. Chandrasekhar, J. D. Madura, R. W. Impey and M. L. Klein; "Comparison of Simple Potential Functions for Simulating Liquid Water", J. Chem. Phys., 79, 926 (1983).

Jorgensen, W. L., J. D. Madura and C. J. Swenson; "Optimized Intermolecular Potential Functions for Liquid Hydrocarbon", J. Am. Chem. Soc., 106, 6638 (1984).

Jorgensen, W. L. and J. D. Madura, "Temperature and Size Dependence for MonteCarlo Simulations of TIP4P Water", Mol. Phys., 56, 1381 (1985).

Jorgensen, W. L. and J. Tiradorives; "The OPLS Potencial Functions for Proteins Energy Minimizations for Crystals of Cyclic-Peptides and Crambin"; J. Am. Chem. Soc., 110, 1666 (1988).

Jorgensen, W. L. and M. P. Repasky, "Ab initio and Monte Carlo study of solvent effects on a 1,3-dipolar cycloaddition", Faraday Discussions, 110, 379 (1998).

Kaplow, R., T. A. Rowe and B. L. Averbach; "Atomic Arrangement in Vitreous Selenium", Phys. Rev., 168, 1069 (1968).

Krätschmer, R., K. Binder and D. Stauffer; "Linear and Nonlinear Relaxation and 
Cluster Dynamics Near Critical-Points", J. Stat. Phys., 15, 267 (1976).

Lide, D. R., 78th CRC Handbook of Chemistry and Physics, CRC Press, Boca Raton (1998).

McGreevy, R. L., and L. Pusztai; "Reverse Monte Carlo Simulation: A New Technique for the Determination of Disordered Structures", Mol. Simul., 1, 359 (1988).

McGreevy, R. L. and M. A. Howe; "RMC: Modeling Disordered Structures", Annu. Rev. Mater. Sci., 22, 217 (1992).

McGreevy, R. L.; "Reverse Monte Carlo: Fact and Fiction", J. Non-Cryst. Sol., 156, 949 (1993).

McGreevy, R. L.; "RMC: Progress, Problems, and Prospects", Nuc.Inst. Meth. Phys. Research A, 354, 1 (1995).

Metropolis, N. and S. Ulam; "The Monte Carlo Method", J. Am. Stat. Assoc., 44, 335 (1949).

Metropolis, N., A.W. Rosenbluth, M. N.Rosenbluth, A. H. Teller and E. Teller; "Equation of State Calculations by Fast Computing Machines", J. Chem. Phys., 21, 1087 (1953).

Michels, A. and H. Wijker; "Isotherms of Argon between $0^{\circ} \mathrm{C}$ and $150^{\circ} \mathrm{C}$ and Pressures up to 2900 atmospheres", Physica, 15, 627 (1949).

Mikolaj P. G. and C. J. Pings, "Structure of Liquids. III. An X-Ray Diffraction Study of Fluid Argon", J. Chem. Phys., 46, 1401 (1967).

Oliveira, M. J.; Notas de aula do curso: Tópicos de Mecânica Estatística - Dinâmicas Estocásticas e Métodos de Monte Carlo, IF/USP (1998)

Petkov, V., and G. Yunchov; "Atomic Ordering in Liquid Se by Unconstrained Reverse Monte Carlo Simulations", J. Phys. Condes. Matter, 8, 1869 (1996).

Press, W. H. and S. A.Teukolsky, "Portable Random Number Generators", Comp.Phys., 6, $522(1992 \mathrm{a})$.

Press, W. H., S. A. Teukolsky, W. T. Vetterling, and B. P. Flannery, Numerical recipes in FORTRAN: The art of Scientific Computing, Cambridge U. P., New York, (1992b). 
Pusztai, L. and G. Tóth; "On the Uniqueness of the Reverse Monte Carlo Simulation. I. Simple Liquids, Partial Radial Distribution Functions", J. Phys. Condes. Matter, 2, $3042(1991)$.

Radnai, T. and P. Jedlovszky; "Reverse Monte Carlo Simulation of a Heteronuclear Molecular Liquid: Structural Study of Acetonitrile”, J. Phys. Chem., 98, 5994 (1994a).

Radnai, T., I. Bakó, P. Jedlovszky and G. Pálinkás; "A Reverse Monte Carlo and RISM Integral Equation Study of Liquid Nitrogen”, Mol. Phys., 83, 459 (1994b).

Reif, F., Fundamentals of Statistical and Thermal Physics, McGraw-Hill, New York, (1965).

Santis, A., and D. Rocca; "On the Uniqueness of the Reverse Monte Carlo Simulation for Molecular Liquids", Mol. Simul., 17, 143 (1996).

Silva, F. L. B., B. Svensson, T. Akesson and B. Jönsson; "A New Algorithm for Reverse Monte Carlo Simulations", J. Chem. Phys., 109, 2624 (1998).

Sole, R. V., J. Valls; "Nonlinear Phenomena and Chaos in a Monte-Carlo Simulated Microbial Ecosystem", Bull. Math. Bio., 54939 (1992).

Tang, S. and D. P. Landau; "Monte Carlo Study of Dynamic Universality in TwoDimensional Potts Models", Phys. Rev. B, 36, 567 (1987).

Tildesley, D. J., P. M. Rodger and A. J. Stone; "Atomic Anisotropy and the Structure of Liquid Chlorine", J. Chem. Soc., Faraday Trans. 2, 89 (1987). 